\title{
¿UN NUEVO DERECHO O EL DEBILITAMIENTO DEL ESTADO? GARANTÍA DE AUDIENCIA PREVIA EN LA EXPROPIACIÓN
}

\author{
A NEW RIGHT OR WEAKING OF THE STATE? \\ GUARANTEE OF PRIOR AUDIENCE IN EXPROPRIATION
}

\author{
Carlos ElizONDO MAYER-SERRA \\ Luis Manuel PÉREZ DE ACHA
}

RESUMEN: La expropiación fue uno de los instrumentos centrales de los gobiernos post revolucionarios. Se efectuaron diversos abusos sobre todo porque no le era aplicable la garantía de audiencia previa establecida en el artículo 14 constitucional. Sin este criterio no hubiera sido posible la nacionalización del petróleo ni la bancaria. No obstante, a principios de 2006 la SCJN emitió un criterio con el cual toda expropiación debe conferir obligatoriamente a los propietarios el derecho de audiencia previa. Los autores, en consecuencia, analiza las razones e implicaciones de tal situación, poniendo especial énfasis en las circunstancias que la rodearon.

Palabras clave: audiencia previa; garantías sociales; expropiación; tribunales administrativos; tribunales judiciales.
ABSTRACT: Expropriation was one of the central tools used by the post revolutionary governments. There were diverse abuses, mainly because it was not possible the use of the guarantee of prior audience established in the article 14. Without this criteria it would have been impossible the nationalization of petroleum and of the banking system. Nevertheless, at the beginning of 2006, the Supreme Court enacted criteria in which it says all expropriations must give the owners the guarantee of prior audience. The author, thereby, analyzes the reasons and implications of such situation, giving special emphasis to the circumstances around it.

Descriptors: Prior Audience, Social Guarantees, Expropriation, Administrative Courts, Judicial Courts. 


\section{INTRODUCCIÓN}

Se suele aceptar que el 6 de julio de 1994 es la fecha en la que da inicio la democracia en México. El triunfo de Vicente Fox lleva al primer gobierno no prí́sta al Poder Ejecutivo. Es, de hecho, el primer cambio de régimen en la historia de México a través del voto. Sin embargo, si hemos de ser más precisos, siguiendo a Przeworski, las elecciones son la forma de llegar al poder desde que existen reglas que permiten que éstas sean libres y competitivas, por lo que quizás es mejor señalar como fecha del inicio de nuestro nuevo régimen el 6 de julio de 1997, cuando la oposición gana el Congreso e inicia la separación entre el Poder Legislativo y el Ejecutivo. ${ }^{1}$

Lo cerrado de la última elección presidencial parece poner en duda este cambio fundamental. Sin embargo, existe un sólido marco institucional para dirimir controversias que es muy superior al existente en casi cualquier otro país del mundo. Al mismo tiempo los partidos políticos de oposición tienen recursos y acceso a medios de comunicación significativos.

El tema, por supuesto, es controversial, sobre todo para los actores políticos que se han visto desfavorecidos con las decisiones emitidas por los órganos y tribunales electorales. Debe, además, tenerse presente que Andrés Manuel López Obrador, el candidato de izquierda, había sido objeto de un procedimiento legal de desafuero, inusitado por la fuerza impuesta por distintos órganos federales, que en opinión de ciertos actores, tenía como propósito central eliminarlo de la contienda presidencial.

Aunque se puede discutir la naturaleza de la elección presidencial del 2006, las elecciones federales son, en general, incuestionablemente libres y competitivas; nadie por ejemplo niega que esto haya sido el caso en las legislativas de ese mismo año. Unas elecciones libres y competitivas han llevado al fortalecimiento del Poder Legislativo y, en general, a una notable descentralización del poder hacia las entidades federativas. Sin embargo, el respeto a las decisiones del votante es sólo una de las facetas de la construcción de un nuevo régimen, al permitir una dispersión del poder y la independencia del Poder Legislativo.

1 Przeworski., Adam et al., Democracy and Development: Political Institutions and Well-Being in the World, 1950-1990, Cambridge-Nueva York, Cambridge University Press, 2000, p. 16. 
Otra faceta es la construcción un Poder Judicial autónomo, que inicia con la reformas de 1995 introducidas por el presidente Zedillo, que dieron al Poder Judicial una protección institucional para ser autónomo. ${ }^{2}$ Es el equivalente al 6 de julio de 1997 para el Poder Legislativo. Con estas reformas la Suprema Corte de Justicia de la Nación (SCJN) obtiene condiciones de seguridad en el empleo de los ministros y autonomía presupuestal que le permite empezar a jugar un papel independiente.

Es el inicio de una verdadera separación de poderes en lo que se refiere al Poder Judicial. Ello no significa que éste no haya tenido cierto margen de autonomía. Lo tuvo en más de un ámbito; pero en los temas políticamente sensibles, las presiones para que se disciplinara eran de muchos tipos, incluida la remoción de los miembros de la SCJN, con lo cual se mantenía la disciplina de los jueces en los casos más sensibles.

La nueva SCJN ha ido ganando en sus sentencias una bien merecida reputación de independencia respecto de los otros dos poderes de la Unión. Sus decisiones más emblemáticas son discutidas en este seminario. Nosotros vamos a analizar la que transforma de raíz uno de los instrumentos centrales en la construcción del régimen posrevolucionario: su capacidad de expropiar sin indemnización ni audiencia previa.

La expropiación fue uno de los instrumentos centrales de los gobiernos posrevolucionarios. Fue piedra fundamental de la reforma agraria contra la cual incluso, por las reformas constitucionales, resultaba improcedente el juicio de amparo para evitar cualquier interpretación contraria a la misma. Algunos de los actos políticos más significativos del siglo $\mathrm{XX}$ fueron expropiaciones como la petrolera y la bancaria, así como las relacionadas con la reforma agraria.

Sin embargo, la expropiación fue también fuente de abusos. Incluso cuando se hacían obras indispensables para la sociedad, como carreteras o aeropuertos, era frecuente que no se indemnizara a los dueños o se les pagara una cantidad ridículamente baja. El abuso podía ser descarado cuando se utilizaba con el objetivo de afectar la propiedad de adversarios políticos. Esa amenaza potencial era por supuesto un disuasivo importante a la participación política de los empresarios en contra del gobierno.

Una de las razones que hacía muy poderoso un decreto expropiatorio es que durante varias décadas, el Pleno de la SCJN sostuvo el criterio jurisprudencial en materia de expropiación, prevista en el artículo 27 , se-

2 Véase La reforma judicial en México, México, SCJN, 2006, cap. III. 
gundo párrafo de la Constitución federal, de que era inaplicable la garantía de audiencia previa establecida en el artículo 14 constitucional. El Estado tomaba la propiedad y luego averiguaba.

Esto, no obstante, dio un giro de casi 180 grados a principios de $2006 .{ }^{3}$ En sesiones públicas celebradas los días 10,12 y 16 de enero, el Pleno de la SCJN emitió un nuevo criterio sustentado por mayoría de 8 de sus 11 ministros, en el cual se determina que en toda expropiación practicada por cualquier nivel de gobierno - Federación, entidades federativas o municipios - 4 es obligatorio, para efectos del artículo 14, segundo párrafo de la Constitución, conferir a los propietarios de los bienes el derecho de audiencia previa, en forma tal que, con antelación a la emisión de los decretos expropiatorios, se les permita formular alegaciones fácticas y legales, así como aportar los elementos probatorios que procedan en aras de acreditar, en su caso, la improcedencia de la expropiación, de cuestionar la causa de utilidad pública aducida por el Estado, o de rebatir la posible infravaloración de los bienes a expropiarse.

La decisión se tomó en medio de la elección más competida en la historia de la política mexicana, cuando López Obrador parecía tener una ventaja cómoda y era visto por ciertos sectores como una amenaza a sus derechos de propiedad. Al habérsele asignado el calificativo del "candidato del miedo", se dejaba ver que uno de los mecanismos que podría utilizar como herramienta de control político, serían las expropiaciones. Si hubiese alcanzado la Presidencia, como resultado de la decisión de los ministros no electos por la gente, habría llegado con una restricción importante de haber querido utilizar la expropiación como instrumento para alcanzar sus fines, una posibilidad que muchos consideraban altamente probable.

3 En realidad, el cambio de criterio había estado fraguándose desde 1997, como consta en los votos particulares de disidencia emitidos por los ministros Genaro David Góngora Pimentel, Sergio Salvador Aguirre Anguiano, José de Jesús Gudiño Pelayo y Juan N. Silva Meza, en los amparos en revisión 1565/94, 2107/91 y 2141/93 resueltos por el Pleno de la SCJN en sesiones de fechas 25 y 27 de febrero y 3 de abril de 1997. Dichos votos particulares se localizan en el Semanario Judicial de la Federación y su Gaceta, t. V, mayo de 1997, pp. 378 y 391, y t. VI, agosto de 1997, p. 435, respectivamente, registros 740,739 y 805 .

4 La SCJN ha aceptado que las leyes locales pueden otorgar facultades expropiatorias a los municipios, según consta en la tesis "AYUNTAMIENTOS, EXPROPIACIONES DECRETADAS POR LOS”, Semanario Judicial de la Federación, t. XLI, p. 492, registro 336,172. Sobre el mismo tema véanse las tesis con registros 211,458, 337 y 379. 
Esta decisión de la SCJN se dio al mismo tiempo que el Ejecutivo hacía esfuerzos por proponer iniciativas tendentes a la creación de instituciones autónomas en materia regulatoria y fiscal, con el fin explícito de limitar el margen de maniobra de un potencial futuro gobierno de izquierda; objetivo que no pudo concretarse por la fuerte presión política del PRD y de algunos medios de comunicación.

El cambio en la jurisprudencia de la SCJN, sin embargo, pasó más bien desapercibido. Mientras que el desafuero de López Obrador generó una amplia movilización social y las reformas a Pemex conllevaron una vociferante reacción de la izquierda, el debilitamiento de uno de los instrumentos preferidos del nacionalismo revolucionario pasó casi desapercibido para los medios de comunicación y los principales analistas. Fue noticia unos cuantos días, y no muy importante.

En este texto nos proponemos analizar las razones e implicaciones de tal decisión, que termina con uno de los instrumentos más poderosos del régimen posrevolucionario: la capacidad de expropiar. Con esta nueva interpretación de la Constitución no hubiera sido posible la nacionalización del petróleo ni la bancaria. Ambas fueron tomadas en secreto, única forma probablemente de hacerlo, dado el peso político de los afectados. Para algunos pensadores, como Arnaldo Córdoba, la nación mexicana se construyó expropiando. No se trata de un instrumento más del gobierno, sino de "El" instrumento. 5

El cambio de jurisprudencia no sólo es importante por el caso concreto que acá analizamos, sino porque muestra también cómo, a final de cuentas, la Constitución es lo que los ministros definen que sea. No se modificó una coma en la Constitución; sin embargo, ahora tiene un significado opuesto a como se había entendido durante 70 años. De golpe, un cuerpo no electo de manera popular pudo darle un significado distinto a la capacidad de expropiar del Estado mexicano.

¿Cómo se justificó jurídicamente esta decisión? Para efectos metodológicos, ¿es mejor este nuevo criterio que el anterior? ¿Por qué los alcances y efectos del nuevo criterio del Pleno y de la nueva jurisprudencia de la Segunda Sala fueron posteriormente modificados para reconocerse que en algún tipo de expropiaciones sí debe observarse la garantía de audiencia previa? ¿Por qué tanta volatilidad e inestabilidad en las decisiones de la SCJN en esta materia? ¿Cuáles son las implicaciones de estos criterios

5 Córdoba, A., "Nación y nacionalismo", Nexos, México, núm. 83, 1984, pp. 27-33. 
para el ciudadano y para el Estado? ¿Qué nos dice del papel político de la SCJN el que se tomara una decisión como ésta en el momento en que se hizo y cuáles serán las implicaciones de haberlo hecho? ¿Por qué no ha tenido el impacto mediático que uno supondría en un país donde cualquier sospecha de cambio legislativo que debilite al Estado revolucionario es motivo de fuertes e inmediatas reacciones?

\section{ASPECTOS CONSTITUCIONALES Y LEGALES \\ DE LA EXPROPIACIÓN}

Conviene iniciar con las bases constitucionales del debate. Son dos los artículos en tensión: el 14 y el 27.

\section{Artículo 14 de la Constitución federal}

En cuanto hace a este precepto, los criterios tradicionales de la SCJN se han orientado, por una parte, en el sentido de que la garantía de audiencia previa sólo comprende actos de autoridad que impliquen la "privación" de los bienes jurídicos ahí señalados: libertad, propiedades, posesiones o derechos. De no darse esta afectación en forma de "privación", no se surte la garantía de audiencia previa en los términos establecidos en aquel artículo, como lo ha señalado la jurisprudencia siguiente:

En los casos en que los actos reclamados impliquen privación de derechos, existe la obligación por parte de las autoridades responsables de dar oportunidad al agraviado para que exponga todo cuanto considere conveniente en defensa de sus intereses; obligación que resulta inexcusable aun cuando la ley que rige el acto reclamado no establezca tal garantía, toda vez que el artículo 14 de la Constitución federal impone a todas las autoridades tal obligación y, consecuentemente, su inobservancia dejaría a su arbitrio decidir acerca de los intereses de los particulares, con violación de la garantía establecida por el invocado precepto constitucional. ${ }^{6}$

6 “AudienCiA, ALCANCE DE LA GARANTÍA DE”, Semanario Judicial de la Federación y su Gaceta, Apéndice 1995, t. VI, primera parte, p. 54, jurisprudencia, núm. 82, registro 394,038. 
Los lineamientos fijados por la SCJN para que se tenga por acatada la garantía constitucional de audiencia previa, aparecen en la siguiente jurisprudencia:

La garantía de audiencia establecida por el artículo 14 constitucional consiste en... en el juicio que se siga "se cumplan las formalidades esenciales del procedimiento". Éstas son las que resultan necesarias para garantizar la defensa adecuada antes del acto de privación y que, de manera genérica, se traducen en los siguientes requisitos: 1) la notificación del inicio del procedimiento y sus consecuencias; 2) la oportunidad de ofrecer y desahogar las pruebas en que se finque la defensa; 3) la oportunidad de alegar; y 4) el dictado de una resolución que dirima las cuestiones debatidas. De no respetarse estos requisitos, se dejaría de cumplir con el fin de la garantía de audiencia, que es evitar la indefensión del afectado. ${ }^{7}$

En todo caso, los gobernados que se vean afectados por actos de autoridad que no impliquen la "privación" de alguno de los bienes jurídicos señalados, sino de "molestia", tendrán la protección de la garantía de legalidad y debido proceso legal prevista en el artículo 16, primer párrafo de la Constitución que señala que: "Nadie puede ser molestado en su persona, familia, domicilio, papeles o posesiones, sino en virtud de mandamiento escrito de la autoridad competente, que funde y motive la causa legal del procedimiento".

Ello ha sido establecido por la SCJN en la tesis que a continuación se transcribe:

En los términos del artículo 14, párrafo segundo, de la Constitución federal, la audiencia previa a la emisión del acto de autoridad y el debido proceso legal, como garantías del gobernado, son de observancia obligatoria únicamente tratándose de actos privativos, sea de la vida, de la libertad, de propiedades, posesiones o derechos de los particulares mas no así cuando se trata de actos de molestia que no tengan la finalidad de privar al afectado de alguno de sus bienes o derechos, pues tales actos se rigen solamente por la garantía

7 "FormalidADES ESENCIALES DEL PROCEDIMIENTO. SON LAS QUE GARANTIZAN UNA ADECUADA Y OPORTUNA DEFENSA PREVIA DEL ACTO PRIVATIVO", Semanario Judicial de la Federación y su Gaceta, t. II, diciembre de 1995, p. 113, registro 200,234, tesis P./J. $47 / 95$. 
de seguridad jurídica (fundamentación y motivación) que establece el artículo 16 constitucional. $^{8}$

Igual criterio se ha sustentado en la siguiente jurisprudencia de la propia SCJN:

Por consiguiente, la Constitución Federal distingue y regula de manera diferente los actos privativos respecto de los actos de molestia, pues a los primeros, que son aquellos que producen como efecto la disminución, menoscabo o supresión definitiva de un derecho del gobernado, los autoriza solamente a través del cumplimiento de determinados requisitos precisados en el artículo 14, como son, la existencia de un juicio seguido ante un tribunal previamente establecido, que cumpla con las formalidades esenciales del procedimiento y en el que se apliquen las leyes expedidas con anterioridad al hecho juzgado. En cambio, a los actos de molestia que, pese a constituir afectación a la esfera jurídica del gobernado, no producen los mismos efectos que los actos privativos, pues sólo restringen de manera provisional o preventiva un derecho con el objeto de proteger determinados bienes jurídicos, los autoriza, según lo dispuesto por el artículo 16, siempre y cuando preceda mandamiento escrito girado por una autoridad con competencia legal para ello, en donde ésta funde y motive la causa legal del procedimiento. Ahora bien, para dilucidar la constitucionalidad o inconstitucionalidad de un acto de autoridad impugnado como privativo, es necesario precisar si verdaderamente lo es y, por ende, requiere del cumplimiento de las formalidades establecidas por el primero de aquellos numerales, o si es un acto de molestia y por ello es suficiente el cumplimiento de los requisitos que el segundo de ellos exige. Para efectuar esa distinción debe advertirse la finalidad que con el acto se persigue, esto es, si la privación de un bien material o inmaterial es la finalidad connatural perseguida por el acto de autoridad, o bien, si por su propia índole tiende sólo a una restricción provisional. ${ }^{9}$

En esta parte cabe formular un señalamiento. A pesar de que el artículo 14 , segundo párrafo, de la Constitución señala que únicamente los tri-

8 “AUDIENCIA Y SEGURIDAD JURÍDICA, GARANTÍAS DE. ACTOS PRIVATIVOS Y ACTOS DE MOLESTIA DE BIENES O DERECHOS. DisTINCIÓN. ARTíCUlOS 14 Y 16 CONSTITUCIONALES", Semanario Judicial de la Federación y su Gaceta, vol. 81, tercera parte, p. 15 , registro 238,355 .

9 "ACtOS PRIVATIVOS Y ACTOS DE MOLESTIA. ORIGEN Y EFECTOS DE LA DISTINCIÓN”, Semanario Judicial de la Federación y su Gaceta, t. IV, julio de 1996, p. 5, Jurisprudencia P./J. 40/96. 
bunales del país tienen la facultad de "privar" a los gobernados de su libertad, propiedades, posesiones o derechos, ya desde 1936, a partir del hecho de que la administración pública tiene una participación marcada $-\mathrm{y}$ desde entonces creciente - en el funcionamiento del Estado, la SCJN permitió que también las autoridades administrativas "privaran" a los particulares de dichos bienes jurídicos sin necesidad de acudir a los tribunales. En el respectivo criterio la SCJN sostiene lo siguiente:

La garantía que otorga el artículo 14 de la Constitución, sobre la necesidad de un juicio previo, para que pueda privarse a los ciudadanos de sus propiedades y derechos, se cumple satisfactoriamente cuando se trata de actos administrativos, si la autoridad que la dicta o ejecuta se ha ceñido estrictamente a las normas del procedimiento, señalado por la ley, ya que la connotación de ser "oído y vencido", no puede referirse sino a la existencia en la ley, de un procedimiento especial, en el que se dé audiencia al interesado y oportunidad para rendir sus pruebas. ${ }^{10}$

En una subsecuente tesis de la SCJN, conocida como tesis Fraga - el apellido del ministro que la promovió-, se reitera dicho criterio en los términos siguientes:

Haciendo un análisis detenido de la garantía de audiencia para determinar su justo alcance, es menester llegar a la conclusión de que si ha de tener verdadera eficacia, debe constituir un derecho de los particulares no sólo frente a las autoridades administrativas y judiciales... Esto no quiere decir, desde luego, que el procedimiento que se establezca en las leyes, a fin de satisfacer la exigencia constitucional de audiencia del interesado, cuando se trate de privarle de sus derechos, tenga necesariamente los caracteres del procedimiento judicial pues bien pueden satisfacerse los requisitos a que se contrae la garantía, mediante un procedimiento entre las autoridades administrativas, en el cual se dé al particular afectado, la oportunidad de hacer su defensa y se le otorgue un mínimo de garantías que le aseguren la posibilidad de que, rindiendo las pruebas que estime convenientes, y formulando los alegatos que crea pertinentes, aunque no tenga la misma formalidad que en el procedi-

10 Tesis “AUTORIDADES ADMINISTRATIVAS, CONSTITUCIONALIDAD DE LOS ACTOS DE LAS”, Semanario Judicial de la Federación, t. LII, p. 2246, registro 333,093. Este criterio quedó reiterado en 1994 en la tesis "AUDIENCIA, GARANTÍA DE COMO QUEDA CUMPLIDA, EN EL PROCEDIMIENTO ADMINISTRATIVO”, Semanario Judicial de la Federación, t. LXXIX, p. 5919, registro 324,092. 
miento judicial, la autoridad que tenga a su cargo la decisión final, tome en cuenta tales elementos, para dictar una resolución legal y justa. ${ }^{11}$

Lo anterior lleva a la conclusión de que la garantía de audiencia previa tiene que respetarse en los casos en que los tribunales o las autoridades administrativas emitan actos "privativos" de la libertad, propiedades, posesiones o derechos de los particulares. Sin embargo, a pesar de que el texto literal del artículo 14, segundo párrafo de la Constitución federal no establece excepciones al respecto, la $\mathrm{SCJN}$, en funciones de intérprete máximo de la Constitución, ha establecido casos en los que la garantía de audiencia no debe ser previa, sino que puede ser posterior al acto de "privación".

Algunas de esas excepciones se basan en el texto constitucional, como sucede con la expulsión de extranjeros cuya estancia en territorio nacional se considere inconveniente por parte del Presidente de la República, caso en el cual el artículo 33, primer párrafo, de la Constitución, expresamente establece que dicho acto es ejecutable "sin necesidad de juicio previo". Las demás excepciones establecidas en esta materia por la SCJN carecen de un sustento constitucional de igual índole, lo que reduce la temática al fenómeno de la interpretación constitucional, con las variables subjetivas e incidentales que se presentan por ese motivo.

Hasta antes de la emisión del nuevo criterio en materia expropiatoria, los casos de excepción a la garantía de audiencia previa eran los especificados en diversas tesis de la SCJN, los cuales quedaron sintetizados en la exposición del ministro Guillermo Ortiz Mayagoitia en la sesión pública del 12 de enero de 2006, en los siguientes términos:

... sólo hay cuatro casos en los que esta Suprema Corte ha dicho que no rige la garantía de audiencia, había uno más en materia de educación, pero fue reformado el 3o. constitucional; estas excepciones son las que contiene el ar-

11 Tesis “AUdiEnCIA, GARANTÍA DE”, Semanario Judicial de la Federación, t. LXXX, p. 3819, registro 323,723. En igual sentido véase la jurisprudencia "ACTOS ADMINISTRATIVOS, INCONSTITUCIONALIDAD DE LOS. NO ES NECESARIO RECLAMAR LA INCONSTITUCIONALIDAD DE LA LEY, CUANDO ÉSTA ES TOTALMENTE OMISA RESPECTO DEL CUMPLIMIENTO DE LAS FORMALIDADES ESENCIALES CONSA- GRADAS POR EL ARTículo 14 CONSTITUCIONAL", Semanario Judicial de la Federación, tercera parte, t. CVIII, p. 99, registro 807,600; y la tesis "AUDIENCIA, GARANTÍA DE. SU CUMPLIMIENTO EN MATERIA ADMINISTRATIVA”, Semanario Judicial de la Federación, vol. 217-228, séptima parte, p. 66, registro 245,018. 
tículo 16 de la Constitución para la orden de aprehensión, pero ésta se explica porque la orden de aprehensión no es un acto privativo todavía; es una medida precautoria, necesaria, para llevar a cabo el proceso penal con presencia del inculpado, por el principio de que no se puede juzgar en ausencia en materia penal, el otro caso es el 27 constitucional por las razones que acabo de comentar; el 31 constitucional en cuanto al cobro de impuestos; el 31 constitucional está fuera ya del capítulo de garantías individuales, y se refiere a una obligación de los mexicanos a contribuir al gasto público...

El artículo 33 constitucional que ya se mencionó libera de la necesaria audiencia previa aquellos casos en los que se da la expulsión del país de lo que se ha llamado coloquialmente un extranjero indeseable. ${ }^{12}$

De este modo, salvo la excepción expresa prevista en el artículo 33, primer párrafo de la Constitución Federal, los demás supuestos son resultado de la labor interpretativa de la SCJN.

\section{Artículo 27 de la Constitución federal}

El artículo 27, primer párrafo, de la Constitución federal instituye la propiedad originaria del Estado sobre las tierras y aguas, en los siguientes términos:

La propiedad de las tierras y aguas comprendidas dentro de los límites del territorio nacional, corresponde originariamente a la Nación, la cual ha tenido y tiene el derecho de transmitir el dominio de ellas a los particulares, constituyendo la propiedad privada.

Esta disposición no estaba incorporada en el artículo 27 del Proyecto de Constitución federal de $1917,{ }^{13}$ cuyo texto original había sido extraído de la Constitución de 1857, para solamente proponer que:

La propiedad privada no puede ocuparse para uso público, sin previa indemnización. La necesidad o utilidad de la ocupación deberá ser declarada por la autoridad administrativa correspondiente; pero la expro-

12 Versión estenográfica de la sesión pública del 12 de enero de 2006, p. 7.

13 En realidad, el Constituyente de 1916-1917 tuvo como propósito la reforma a la Constitución de 1857. 
piación se hará por la autoridad judicial, en el caso de que haya desacuerdo sobre sus condiciones entre los interesados. ${ }^{14}$

En relación con esta propuesta de texto, del mensaje de Venustiano Carranza resalta lo siguiente:

El artículo 27 de la Constitución de 1857 faculta para ocupar la propiedad de las personas sin el consentimiento de ellas y previa indemnización, cuando así lo exija la utilidad pública. Esta facultad es, a juicio del gobierno de mi cargo, suficiente para adquirir tierras y repartirlas en la forma que se estime conveniente entre el pueblo que quiera dedicarse a los trabajos agrícolas, fundando así la pequeña propiedad, que debe fomentarse a medida que las públicas necesidades lo exijan.

La única reforma que con motivo de este artículo se propone, es que la declaración de utilidad sea hecha por la autoridad administrativa correspondiente, quedando sólo a la autoridad judicial la facultad de intervenir para fijar el justo valor de la cosa de cuya expropiación se trata. ${ }^{15}$

Fue entonces que varios diputados del Congreso Constituyente de 1916-191716 presentaron una iniciativa de modificaciones al artículo 27 del Proyecto de Constitución, para instituir la propiedad originaria del Estado sobre las tierras y aguas en territorio nacional. ${ }^{17}$ Las razones para justificar este planteamiento fueron las siguientes:

El artículo 27 tendrá que ser el más importante de todos cuantos contenga la Constitución que el H. Congreso viene elaborando. En este artículo tiene por fuerza que sentarse los fundamentos sobre los cuales deberá descansar todo el

14 Derechos del Pueblo Mexicano: México a través de sus Constituciones, México, Cámara de Diputados, 2000, vol. 1, p. 340.

15 Ibidem, p. 339.

16 Los diputados fueron Pastor Rouaix, Julián Adame, D. Pastrana J., Pedro A. Chapa, José Álvarez, José N. Macías, Porfirio del Castillo, Federico E. Ibarra, Rafael L. de los Ríos, Alberto Terrones B., S. de los Santos, Jesús de la Torre, Silvestre Dorador, Dionisio Zavala, E. A. Enríquez, Antonio Gutiérrez, Rafael Martínez de Escobar y Rubén Martí.

17 Esta iniciativa fue presentada en la sesión del 25 de enero de 1917, y en realidad constituyó la propuesta para un nuevo artículo 27 de la Constitución, distinta por completo a la contenida en el proyecto inicial, aunque integrando algunas partes de éste. 
sistema de los derechos que pueden tenerse a la propiedad raíz comprendida dentro del territorio nacional.

La propiedad, tal cual ha llegado hasta nosotros, se formó durante la época colonial, y es extremadamente compleja. El principio absoluto de la autoridad del rey, dueño de las personas y de los bienes de sus súbditos, dio a la propiedad, sobre todos esos bienes, el carácter de precaria; todo podía ser de dichos súbditos, en tanto que la voluntad del rey no dispusiera lo contrario.

Por virtud precisamente de existir en dicha legislación colonial el derecho de propiedad absoluta en el rey, bien podemos decir que ese derecho ha pasado con el mismo carácter a la nación. En tal concepto, la nación viene a tener el derecho pleno sobre las tierras y aguas de su territorio, y sólo reconoce u otorga a los particulares, el dominio directo, en las mismas condiciones en que se tuvo por los mismos particulares durante la época colonial y en las mismas condiciones en que la República después lo ha reconocido u otorgado... La primera parte del texto que proponemos para el artículo 27, da clara idea de lo que exponemos... En efecto, la nación, reservándose sobre todas las propiedades el dominio supremo, podrá, en todo tiempo, disponer de las que necesite regular el estado de la propiedad total, pagando las indemnizaciones correspondientes. ${ }^{18}$

Como parte de la propuesta del mismo grupo de diputados se incluía la incorporación de una fracción XII al propio artículo 27, para establecer que:

La necesidad o utilidad de la ocupación de una propiedad privada, de acuerdo con las bases anteriores, deberá ser declarada por la autoridad administrativa correspondiente. El precio que se fijará como indemnización a la cosa expropiada se basará en la cantidad que como valor fiscal de ella figure en las oficinas catastrales o recaudadoras, ya sea que este valor haya sido manifestado por el propietario o simplemente aceptado por él de un modo tácito, por haber pagado sus contribuciones con esta base, aumentándola con un diez por ciento. El exceso o valor que haya tenido la propiedad particular por las mejoras que se le hubieren hecho con posterioridad a la fecha de asignación del valor físcal, será lo único que deberá quedar sujeto a juicio pericial y a resolución

18 Derechos del Pueblo Mexicano: México a través de sus Constituciones, México, Cámara de Diputados, 2000, vol. 1, pp. 483-485. Para un análisis detallado de los trabajos de la Comisión, véase Rouaix, Pastor, Génesis de los artículos 27 y 123 de la Constitución Política de 1917, México, IEHR, 1959. 
judicial. Esto mismo se observará cuando se trate de objetos cuyo valor no esté fijado en las oficinas rentísticas.

En sesión del 29 de enero de 1917 se presentó el dictamen sobre el artículo 27 del Proyecto de Constitución, que en su parte relativa señalaba lo siguiente:

Es un principio admitido sin contradicción, que el dominio eminente del territorio mexicano pertenece originariamente a la nación; lo que constituye y ha constituido la propiedad privada es el derecho que ha cedido la nación a los particulares, cesión en la que no ha podido quedar comprendido el derecho a los productos del subsuelo ni a las aguas, como vías generales de comunicación.

Como consecuencia de lo expuesto, la Comisión, después de consagrar la propiedad como garantía individual, poniéndola a cubierto de toda expropiación que no esté fundada en la utilidad pública, ha fijado las restricciones a que está sujeto ese derecho.

Finalmente, el artículo 27 quedó aprobado en los términos como actualmente está redactado. Es de enfatizarse el hecho que en el texto del Proyecto de Constitución de 191719 el adjetivo "previa" calificaba a la indemnización en los casos de expropiación; sin embargo, la palabra "previa" desapareció del texto definitivo, sustituyéndose por "mediante" al referirse a la indemnización, sin que conste explicación alguna en la iniciativa de modificaciones al proyecto, del 25 de enero de 1917, ni en el dictamen leído el 29 siguiente. $^{20}$

19 Anteriormente, el artículo 27, primer párrafo, de la Constitución de 1857 establecía: "La propiedad de las personas no puede ser ocupada sin su consentimiento, sino por causa de utilidad pública y previa indemnización. La ley determinará la autoridad que deba hacer la expropiación y los requisitos con que ésta haya de verificarse". En los debates en el Congreso Constituyente de 1856-1857 para la aprobación de este artículo, que tuvieron lugar los días 14 de agosto y 28 de noviembre de 1856, no consta aclaración o precisión alguna que permita resolver en sentido afirmativo o negativo el sentido de los términos “ocupación” y “expropiación”, Zarco, F., Congreso Extraordinario Constituyente 1856-1857, El Colegio de México, Secretaría de Gobernación, México, 1979, pp. 478 y 795 .

20 El artículo 27 de la Constitución de 1857 también exigía que la indemnización fuera "previa" a la expropiación. Otro dato relevante es que las figuras de "expropiación" y "ocupación" se utilizaron a la par en ambos documentos. Adicionalmente, los vocablos 
Comentarios por separado amerita la fracción VI del artículo 27 de la Constitución, en concreto sus párrafos segundo y tercero. En éstos se establecen — quizá con sentido disímil - los conceptos "ocupación" y "expropiación" que, al igual que en el texto de la Constitución Federal de 1857, del Proyecto de Constitución de 1916-1917 y de la propuesta realizada por varios diputados el 25 de enero de 1917, se utilizan con significados distintos. Los párrafos originalmente aprobados, y que aún continúan en vigor, establecen lo siguiente:

Las leyes de la Federación y de los estados en sus respectivas jurisdicciones, determinarán los casos en que sea de utilidad pública la ocupación de la propiedad privada, y de acuerdo con dichas leyes la autoridad administrativa hará la declaración correspondiente. El precio que se fijará como indemnización a la cosa expropiada, se basará en la cantidad que como valor fiscal de ella figure en las oficinas catastrales o recaudadoras, ya sea que este valor haya sido manifestado por el propietario o simplemente aceptado por él de un modo tácito por haber pagado sus contribuciones con esta base. El exceso de valor o el demérito que haya tenido la propiedad particular por las mejoras o deterioros ocurridos con posterioridad a la fecha de la asignación del valor fiscal, será lo único que deberá quedar sujeto a juicio pericial y resolución judicial. Esto mismo se observará cuando se trate de objetos cuyo valor no esté fijado en las oficinas rentísticas.

El ejercicio de las acciones que corresponden a la nación, por virtud de las disposiciones del presente artículo, se hará efectivo por el procedimiento judicial; pero dentro de este procedimiento y por orden de los tribunales correspondientes, que se dictará en el plazo máximo de un mes, las autoridades administrativas procederán desde luego a la ocupación, administración, remate o venta de las tierras o aguas de que se trate y todas sus accesiones, sin que en ningún caso pueda revocarse lo hecho por las mismas autoridades antes que se dicte sentencia ejecutoriada.

Ahora bien, en el párrafo segundo de la fracción VI antes transcrito, se reitera el uso de los términos "ocupación" y "expropiación", con distinta

“ocupación” y "previa" datan de la Constitución Federal de 1824, pasando por las Leyes Constitucionales de 1836 y las Bases Orgánicas de 1842. El término "expropiación” fue utilizado junto con "ocupación” y "previa” a partir del Estatuto Orgánico Provisional de 1856, que como tales se tomaron en la Constitución de 1857 y en el Proyecto de Constitución de 1917, como ya hemos apuntado. En fin, todo un desacomodo histórico de la terminología constitucional utilizada en esta materia. 
connotación - al igual que lo hace la Ley de Expropiación en su artículo 20. ${ }^{21}$ se establecen los mecanismos para determinar el valor de los bienes expropiados, y se reconoce que esta materia rige por igual en el ámbito federal y en el de las entidades federativas. ${ }^{22}$

En lo que hace al tercer párrafo de la propia fracción, su análisis ha sido escaso por parte de la SCJN, y si acaso algunos pincelazos se esbozaron en la discusión que los ministros sostuvieron con motivo de la emisión del nuevo criterio en materia expropiatoria, aunque sin llegar a definir claramente sus alcances y mucho menos a reflexionar sobre las condiciones que en el mismo se imponen. Por ello, vale la pena traer a colación el siguiente apunte doctrinal:

En este procedimiento, conforme a la Constitución, la autoridad expropiante tiene la facultad de solicitar al juez, y éste en ese caso la obligación de decretar la ocupación provisional de los bienes expropiados y la administración de los mismos y aun el remate o la venta de las tierras o de las aguas de que se trata y todas sus accesiones; pero esos actos son revocables en el caso de que la sentencia definitiva que se dicte en el juicio sea adversa a la autoridad expropiante...

Evidentemente que la razón de ser del procedimiento de ocupación no es la de efectuar una revisión unilateral de la autoridad judicial, sino una verdadera contención y, por lo mismo, deben ser admitidas al expropiado todas las excepciones que tenga para impedir la ocupación de la cosa expropiada; pero esas excepciones, como es natural, deben ser congruentes con la acción deducida; es decir, deben referirse exclusivamente a los defectos legales de la declaración de la expropiación, a la falta de los requisitos que la ley exige para su procedencia, $o$ a los defectos en el procedimiento; no hay, por lo mismo, ningún inconveniente en que la ley limite las excepciones del demandado a esos capítulos; indudablemente que entre las excepciones que no puede oponer está la de los defectos de la valorización, cuando ésta se haya hecho por el procedimiento judicial, en el que el expropiado haya sido debidamente citado.

Naturalmente que la sentencia definitiva que se pronuncie en este procedimiento, tiene por efecto recuperar el dominio, para el expropiado, o confirmar su

21 Dicha disposición señala: "En los casos comprendidos en la enumeración del artículo 1o., previa declaración del Ejecutivo federal, procederá la expropiación, la ocupación temporal, total o parcial, o la simple limitación de los derechos de dominio para los fines del Estado o en interés de la colectividad".

$22 \mathrm{Y}$, como hemos ya señalado, en el de los municipios, conforme al criterio de la SCJN que ha aceptado que las leyes locales otorguen facultades expropiatorias a los mismos. 
pérdida, a base de la apreciación judicial que se haga sobre la ilegitimidad o legitimidad de la expropiación.

La Ley Federal [de Expropiación] en vez de reglamentar el procedimiento judicial que claramente exige la Constitución, da un recurso administrativo de revocación... ${ }^{23}$

Es oportuno precisar que el artículo 27, fracción VI, segundo y tercer párrafos de la Constitución federal, ha sido objeto de estudio por parte de la SCJN, habiéndose pronunciado al efecto la jurisprudencia que a continuación se transcribe:

Los artículos 2o., 3o., 7o. y 8o. de la Ley de Expropiación no establecen que la autoridad judicial debe intervenir para la ocupación de la propiedad privada en caso de expropiación. El artículo 27, fracción VI, segundo párrafo, de la Constitución de los Estados Unidos Mexicanos, limita la intervención de dicha autoridad a determinados supuestos en los siguientes términos: cuando exista "exceso de valor o demérito que haya tenido la propiedad particular por las mejoras o deterioros ocurridos con posterioridad a la fecha de la asignación fiscal. Esto mismo se observará cuando se trate de un objeto cuyo valor no esté fijado en las oficinas rentísticas". En ningún otro caso se autoriza la intervención de la autoridad judicial. Es inexacto que el tercer párrafo de la fracción VI del artículo 27 constitucional sea complementario del segundo párrafo de la misma fracción y que, por tal razón, pueda la autoridad judicial ordenar la posesión de los bienes expropiados. La disposición del segundo párrafo es autónoma y regula, exclusivamente, lo relativo a la expropiación, limitando la intervención de la autoridad judicial sólo a los casos específicamente determinados. El tercer párrafo, al referirse a "las acciones que corresponden a la nación", no incluye a la expropiación, toda vez que ésta no es una acción que corresponda al Estado como persona de derecho privado... Por consiguiente, la intervención de la autoridad judicial prevista en el citado tercer párrafo solamente es aplicable a las acciones que el propio artículo 27 constitucional confiere a la Federación para lograr que las tierras y aguas ingresen al patrimonio nacional, no así en lo que hace a la posesión de los bienes materia de la expropiación, toda vez que en lo que a este acto de soberanía del Estado se refiere, la intervención de la autoridad judicial está restringida en los términos señalados por el segundo párrafo de la fracción VI del citado precepto constitucional, el cual en su parte final textualmente dice:

23 Fernández del Castillo, G., La propiedad y la expropiación, México, Escuela Libre de Derecho, 1987, s. e., pp. 112 y 113. 
"Será lo único que deberá quedar sujeto a juicio pericial y a resolución judicial". 24

Del análisis de esta jurisprudencia resulta evidente que la misma es congruente con las anteriores, que sostenían que en esta materia era inoperante la garantía de audiencia previa, pues hubiera sido inconsistente que se exigiera la intervención judicial para que las autoridades administrativas "ocuparan" los bienes "expropiados", cuando las propias autoridades, por sí y ante sí - sin participación formal de los sujetos afectados-, podían decretar la "expropiación" de los bienes y, por ende, proceder a la "ocupación" de éstos.

\section{Antecedentes jurisprudenciales}

La interpretación histórica de la SCJN del artículo 27, segundo párrafo de la Constitución, había sido en el sentido de que en materia expropiatoria no operaba la garantía de audiencia previa. Así consta, por ejemplo, en la jurisprudencia integrada de 1939 a 1942 por parte de la Segunda Sala, que señalaba: "En materia de expropiación no rige la garantía de previa audiencia consagrada en el artículo 14 de la Constitución federal, porque ese requisito no está comprendido entre los que señala el artículo 27 de la misma carta fundamental". ${ }^{25}$

Este criterio permaneció inmutable durante varias décadas, y aunque la garantía de audiencia previa se invocaba reiteradamente por los afectados, el mismo seguía confirmándose por la SCJN, ahora por parte de su Pleno, como aparece en la jurisprudencia conformada de 1965 a 1974, que a continuación se transcribe:

En materia de expropiación no rige la garantía de previa audiencia consagrada en el artículo 14 de la Constitución federal, porque ese requisito no está comprendido entre los que señala el artículo 27 de la propia carta magna y no

24 Jurisprudencia núm. 40, "EXPROPIACIÓN. LA OCUPACIÓN DE LA PROPIEDAD NO REQUIERE DE INTERVENCIÓN JUDICIAL", Gaceta del Semanario Judicial de la Federación, vols. 22-24, octubre-diciembre de 1989, p. 37, registro 820,180.

25 Jurisprudencia núm. 834, "EXPROPIACIÓN, LA GARANTÍA DE PREVIA AUDIENCIA NO RIGE EN MATERIA DE”, Apéndice 1988 al Semanario Judicial de la Federación, parte II, p. 1389, registro 395,181. Como se verá con posterioridad, esta jurisprudencia fue objeto de modificación por la propia Segunda Sala de la SCJN, para sostener que la garantía de audiencia previa sí rige en esta materia. 
puede admitirse que exista contradicción entre las disposiciones contenidas en ambos preceptos, por ser evidente que el primero de ellos establece una regla general para derechos subjetivos, mientras que el segundo, ampara garantías sociales, que por su propia naturaleza, están por encima de los derechos individuales a los que restringe en su alcance liberal, en términos del artículo 1o. de la propia ley fundamental. ${ }^{26}$

Aplicada la anterior jurisprudencia sin avatares importantes en las décadas subsecuentes, en 1995, incluso, el propio Pleno de la SCJN instruyó que la misma se publicara de nueva cuenta a efecto de adicionarle el rubro - su contenido es exactamente el mismo-, para quedar: "EXPROPIACIÓN, LA GARANTÍA DE PREVIA AUDIENCIA NO RIGE EN MATERIA DE", a la cual se le asignó el número P./J. 65/95, cuyo texto se transcribe a continuación para efecto de su confronta con la antes transcrita:

En materia de expropiación no rige la garantía de previa audiencia consagrada en el artículo 14 de la Constitución federal, porque ese requisito no está comprendido entre los que señala el artículo 27 de la propia carta magna y no puede admitirse que exista contradicción entre las disposiciones contenidas en ambos preceptos, por ser evidente que el primero de ellos establece una regla general para derechos subjetivos, mientras que el segundo, ampara garantías sociales, que por su propia naturaleza, están por encima de los derechos individuales a los que restringe en su alcance liberal, en términos del artículo 10. de la propia ley fundamental. ${ }^{27}$

\section{NuEVOS CRITERIOS DE LA SCJN}

\section{El criterio del Pleno a partir de 2006}

En sesión pública del Pleno de 10 de enero de 2006, el entonces ministro Juan Díaz Romero presentó el proyecto de sentencia en el amparo en revisión número 1133/2004, cuya materia era un decreto expropiatorio emitido en perjuicio de la empresa quejosa: Fomento Azucarero del

26 Jurisprudencia núm. 65, "EXPROPIACIÓN, LA GARANTÍA DE AUDIENCIA NO RIGE EN MATERIA DE", Apéndice 1995 al Semanario Judicial de la Federación, t. III, p. 46, registro 390,955 .

27 Tesis P./J. 65/95, "EXPROPIACIÓN, LA GARANTÍA DE PREVIA AUDIENCIA NO RIGE EN MATERIA DE”, registro 198,404. 
Golfo, S. A. de C. V. Al abrirse a discusión dicho proyecto, el ministro Sergio Salvador Aguirre Anguiano argumentó lo siguiente:

... yo estoy en contra del proyecto y por la concesión del amparo, pero yo creo que hay algo de previo y especial pronunciamiento que es lo que sigue y que traigo a colación por razón de la nueva integración de la Suprema Corte, antes de esta integración y me refiero a la anterior cuando todavía no eran ministros don Sergio Valls, doña Margarita Luna y el señor ministro Cossío Díaz, se había resuelto mayoritariamente por seis votos a cinco, que sí, que sí (sic) debía de ser audiencia posterior al acto de expropiación, pese a que el Tratado de Libre Comercio de México con Estados Unidos, les diera a los extranjeros la garantía de audiencia previa, hubimos quienes sostuvimos que no, que no podía ser así, que los extranjeros tuvieran más garantías en este país, que los nacionales mexicanos, yo pienso que habiendo cambiado aquella integración, que tomó una decisión ajustada hoy es oportuno que recapitulemos sobre la misma, no será sorpresa para ustedes escuchar que yo como antes, estoy por sostener la audiencia previa, con todas las derivaciones que ello implique. ${ }^{28}$

Este planteamiento fue secundado por el ministro Genaro David Góngora Pimentel, quien al respecto manifestó lo siguiente:

Posiblemente lo propuesto por don Sergio Aguirre Anguiano, sea previo a todo lo demás, la garantía de audiencia previa que en sesión, antes de que estuvieran los tres nuevos ministros, se presentó en Pleno, y si no hubo garantía de audiencia previa, pues para qué vamos a examinar todo lo demás, todo el fondo, debe de concederse garantía de audiencia previa, incluso, darles como dice el Tratado de Libre Comercio, la intención, hacerles conocer la intención de expropiar, y como lo dice también el Tratado de Libre Comercio con Argentina y el Tratado de Libre Comercio con Japón y todos los demás, puesto que éste ( $\mathrm{sic}$ ) es una cláusula de la nación más favorecida que tendrán que tener todos los demás tratados... ${ }^{29}$

Ello propició un amplio debate en el Pleno de la SCJN, que se extendió a la sesiones públicas de los días 12 y 16 de enero de 2006, tanto sobre aspectos sustantivos de índole constitucional relacionados con la interpretación semántica e histórica de los artículos 14, primer párrafo y

28 Versión estenográfica de la sesión pública del 10 de enero de 2006, pp. 9 y 10.

29 Ibidem, p. 11. 
27, segundo párrafo, de la Constitución, como sobre cuestiones procesales del juicio de amparo en la instancia de revisión. La decisión final sustentada por ocho ministros fue en el sentido de votar en contra del proyecto presentado por el ministro Juan Díaz Romero y, en consecuencia, por conceder el amparo en contra del decreto expropiatorio impugnado, al considerar que éste era inconstitucional por no haber respetado la garantía de audiencia en forma previa a su emisión.

El engrose del fallo fue encomendado a la ministra Margarita Beatriz Luna Ramos, y en él destacan las consideraciones y conclusiones siguientes:

- Que las razones contenidas en la jurisprudencia P./J. 65/95 no son del todo correctas, pues es inexacto que la facultad expropiatoria consignada en el artículo 27, segundo párrafo, de la Constitución corresponda a una garantía social, sino que propiamente se trata de un límite constitucional a la afectación de la propiedad privada por parte del Estado.

- Que, incluso, si se tratara de una garantía social, no existiría razón alguna para conferirle una jerarquía superior a la garantía de audiencia previa del artículo 14, primer párrafo, de la Constitución, pues como lo señala la ejecutoria que se comenta, no puede "resolverse de modo absoluto y abstracto" la mayor entidad de las garantías sociales frente las individuales.

- Que el artículo 27, segundo párrafo, de la Constitución sólo establece dos requisitos para que proceda la expropiación: que sea por causa de utilidad pública y que medie indemnización, sin que del texto constitucional se desprenda excepción explícita alguna a la garantía de audiencia previa.

- Que el artículo 14, primer párrafo de la Constitución no establece restricción alguna a la garantía de audiencia previa ante los actos privativos de la propiedad, como la expropiación, ni siquiera ante situaciones urgentes o apremiantes que reclame el orden público o el interés social, pues para estos fines la Ley de Expropiación prevé medidas legales alternativas que permiten la ocupación inmediata de los bienes. En esta parte cabe remarcar que el Pleno de la SCJN concluyó que la garantía de audiencia previa en la expropiación ni 
siquiera admitía como excepciones los casos urgentes o apremiantes exigidos por el orden público o el interés social.

- Que debe existir una relación lógica de correspondencia entre la intensidad de la afectación de un acto expropiatorio y la intensidad de las garantías de defensa frente a posibles actuaciones arbitrarias sobre la propiedad privada, en forma tal que dicha defensa sea efectiva.

En la parte conducente de dicha ejecutoria, la concesión del amparo se produjo de la manera siguiente (foja 135):

En efecto, las autoridades responsables de la emisión de dicho decreto han omitido por completo permitir que la empresa quejosa demuestre que su situación no coincide con los supuestos jurídicos previstos en ese acto administrativo, mediante la instauración de un procedimiento en el que se le emplace y se le den a conocer con precisión todos los documentos y circunstancias de hecho que han llevado a la determinación de la autoridad de expropiar la unidad económica que le pertenece, otorgándole la posibilidad de que demuestre, en su caso, que tal decisión no es la adecuada, y brindándole la oportunidad de alegarlo que a su interés convenga, también previamente al pronunciamiento de la resolución definitiva, todo lo cual conduce a estimar que no se ha respetado el mandato constitucional previsto en el segundo párrafo del artículo 14 constitucional que, como se ha visto, sí opera tratándose de la apropiación de bienes por parte del Estado en términos del artículo 27, segundo párrafo, de la misma Constitución federal, el cual igualmente protege el derecho fundamental a la propiedad privada.

Uno de los efectos directos de esta decisión fue que "se resolvió interrumpir el criterio sustentado en la tesis jurisprudencial número 65/95 EXPROPIACIÓN. LA GARANTÍA DE PREVIA AUDIENCIA NO RIGE EN MATERIA DE..." [folio 138], cuyo fundamento se ubica en el artículo 194, primer párrafo, de la Ley de Amparo, que dispone: "La jurisprudencia se interrumpe dejando de tener carácter obligatorio, siempre que se pronuncie ejecutoria en contrario por ocho ministros, si se trata de la sustentada por el Pleno; por cuatro, si es de una sala, y por unanimidad de votos tratándose de la de un tribunal colegiado de circuito". 


\section{El criterio de la Segunda Sala a partir de 2006}

El nuevo criterio del Pleno de la SCJN tuvo como derivación que su Segunda Sala revisara la diversa jurisprudencia 834 por ella emitida — la integrada en de 1939 a 1942 - , en la que se resolvía, como se explicó, que en materia expropiatoria no regía la garantía de audiencia previa. El mecanismo utilizado no fue la interrupción de esta jurisprudencia, como en su momento lo hizo el Pleno, sino que se optó por emitir una nueva en función de la solicitud de modificación presentada al efecto por el ministro Mariano Azuela Güitrón, en su calidad de presidente de la SCJN - quien no formaba parte de la Segunda Sala—, con el propósito de exigir precisamente eso: el respeto de la garantía de audiencia previa en la expropiación.

El resultado de esa solicitud fue la emisión de la jurisprudencia 2a./J. 124/2006, en cuyo texto se señala:

Conforme al artículo 197 de la Ley de Amparo, la Segunda Sala de la Suprema Corte de Justicia de la Nación modifica la jurisprudencia 834, publicada en el Apéndice al Semanario Judicial de la Federación 1917-1988, segunda parte, p. 1389, con el rubro: "EXPROPIACIÓN, LA GARANTÍA DE PREVIA AUDIENCIA NO RIGE EN MATERIA DE", porque de una nueva reflexión se concluye que de la interpretación del artículo 14, párrafo segundo, de la Constitución Política de los Estados Unidos Mexicanos, los actos privativos de la propiedad deben realizarse, por regla general, mediante un procedimiento dirigido a escuchar previamente al afectado, en el que se cumplan las formalidades esenciales del procedimiento... En ese sentido, tratándose de actos privativos como lo es la expropiación, para que la defensa sea adecuada y efectiva debe ser previa, en orden a garantizar eficazmente los bienes constitucionalmente protegidos a través del mencionado artículo 14, sin que lo anterior se contraponga al artículo 27 de la Constitución federal, pues si bien es cierto que este precepto establece las garantías sociales, las cuales atienden a un contenido y finalidades en estricto sentido al régimen de propiedad agraria, y por extensión a las modalidades de la propiedad, al dominio y a la propiedad nacional, también lo es que la expropiación no es una garantía social en el sentido estricto y constitucional del concepto, sino que es una potestad administrativa que crea, modifica y/o extingue relaciones jurídicas concretas, y que obedece a causas establecidas legalmente y a valoraciones discrecionales de las autoridades administrativas; además, la expropiación es una potestad administrativa dirigida a la supresión de los derechos de uso, disfrute y 
disposición de un bien particular decretada por el Estado, con el fin de adquirirlo. ${ }^{30}$

La situación que pudo presentarse a partir de que el Pleno cambió el criterio en esta materia y, consecuentemente, interrumpió la obligatoriedad de la jurisprudencia P./J. 65/95, fue, por un lado, que el nuevo criterio del Pleno, al ser uno solo - el primero que determinaba la exigencia de la audiencia previa en la expropiación - no integraba jurisprudencia y, por ende, no era obligatorio para las salas ni para los restantes órganos jurisdiccionales del país. Sin embargo, al mismo tiempo la jurisprudencia 834 de la Segunda Sala continuaba en vigor y, por ello, era indiscutiblemente obligatoria en términos del artículo 192, primer párrafo de la Ley de Amparo. Además, se presentaba la paradoja de que, a pesar de que un órgano de jerarquía superior como es el Pleno de la SCJN, exigía el respeto previo de la garantía de audiencia en la expropiación - aunque no en jurisprudencia $\mathrm{y}$, por lo tanto, sin obligatoriedad alguna-, sucedía que otro de jerarquía inferior como la Segunda Sala sustentaba un criterio jurisprudencial en sentido opuesto, que como tal sí era obligatorio.

Situación paradójica, sin lugar a dudas, algunas de cuyas incidencias fueron advertidas por el ministro Juan Díaz Romero en su voto particular, de la siguiente manera:

Ahora bien, del análisis de los antecedentes del presente asunto se advierte que el Tribunal Pleno emitió la jurisprudencia P./J. 65/95, de rubro: "EXPROPIACIÓN. LA GARANTÍA DE PREVIA AUDIENCIA NO RIGE EN MATERIA DE", la cual fue interrumpida en enero de 2006, cuando se sometieron a la decisión del Pleno los amparos en revisión 1131/2004, 1132/2004 y 1133/2004, relacionados con la expropiación de los ingenios azucareros.

Derivado de lo anterior, debe concluirse que el nuevo criterio sustentado por el Pleno constituye un precedente aislado que aún no ha integrado jurisprudencia, motivo por el cual no resulta obligatorio para las salas ni para los demás órganos jurisdiccionales.

De este modo, conviene destacar que existe jurisprudencia de la Segunda Sala en el sentido de que tratándose de expropiaciones no debe regir la garan-

30 Semanario Judicial de la Federación y su Gaceta, t. XXIV, septiembre de 2006, p. 278, registro 174,253, jurisprudencia 2a./J. 124/2006, "EXPROPIACIÓN. LA GARANTÍA DE AUDIENCIA DEBE RESPETARSE EN FORMA PREVIA A LA EMISIÓN DEL DECRETO RELATIVO". 
tía de audiencia previa, la cual, de conformidad con el artículo 192 de la Ley de Amparo, resulta obligatoria para los tribunales colegiados de circuito y órganos jurisdiccionales de menor jerarquía.

Para evitar esta situación contradictoria, la Segunda Sala de la SCJN optó por la vía ya indicada, cuya justificación se plasmó en la ejecutoria que dio pauta a la jurisprudencia 2a./J. 124/2006, de la siguiente manera:

Sobre este tema, de especial relevancia resulta apuntar que aun cuando en el citado numeral [197, último párrafo de la Ley de Amparo] no se señala expresamente al ministro presidente como legitimado para solicitar la modificación de una jurisprudencia, ello no obsta para reconocer que tal circunstancia constituye una omisión del legislador, que debe colmarse a través de la interpretación sistemática de los previsto en la Ley de Amparo y en la Ley Orgánica del Poder Judicial de la Federación.

En efecto, de la lectura detenida del artículo 197 en comento es factible advertir que si el legislador no mencionó al ministro presidente en su último párrafo, ello obedece a que en el párrafo primero de ese mismo numeral también se omitió hacer referencia a dicho servidor público, en virtud de que en este supuesto normativo se hizo mención de las salas de este alto tribunal que por su misma jerarquía pueden incurrir en contradicción te tesis, sin señalar, por ende, al ministro presidente que no integra alguna de aquéllas.

De igual forma, no existe impedimento legal para que la solicitud de modificación derive de un caso concreto que fue resuelto por el Pleno de este alto tribunal, pues si bien tanto el Pleno como las salas tienen fijada su propia esfera de competencia y existe autonomía en el dictado de sus resoluciones, excepción del supuesto previsto en el artículo 192 de la Ley de Amparo en el que las salas se encuentran obligadas a aplicar la jurisprudencia establecida por el Pleno, debe tenerse presente que los criterios aislados del Pleno de la Suprema Corte no interrumpen la jurisprudencia establecida por las salas, lo que tampoco sucede respecto de la jurisprudencia establecida por los tribunales colegiados de circuito.

..

Lo cual es congruente con el fin último, que consagra la modificación de jurisprudencia, esto es, permitir la adecuación de los criterios jurisprudenciales ante la posibilidad de que surjan nuevos elementos de juicio de los que se pueda llegar a estimar que la misma no es la correcta y evitar que los órganos jurisdiccionales de menor jerarquía se apeguen a un criterio que ya fue superado por el tribunal Pleno, lo cual indudablemente genera certeza jurídica a los gobernados sobre el alcance que debe darse al resolver un caso concreto 
respecto del cual exista un criterio jurisprudencial que bajo un nuevo análisis ya no es correcto, pero que por la obligatoriedad de la jurisprudencia tendrían que seguir aplicando.

Al respecto, no escapa señalar que la emisión de la nueva jurisprudencia de la Segunda Sala de la SCJN fue consecuencia de un procedimiento atípico, no sólo porque antecedentes de igual tipo son inexistentes en los anales jurisprudenciales, sino también porque la finalidad de la solicitud no fue la interrupción de la jurisprudencia 834 de la propia Segunda Sala - como en su momento lo efectuó el Pleno con la jurisprudencia P./J. $65 / 95$ - , sino la emisión directa e inmediata de una diversa jurisprudencia.

Es entendible el deseo expuesto en la ejecutoria por asimilar los criterios de la Segunda Sala con la nueva decisión del Pleno en esta materia; sin embargo, si el Pleno no pudo constituir jurisprudencia al respecto por no satisfacerse los requisitos pertinentes, es difícil aceptar que la sola petición de modificación presentada por el presidente de la Corte, hubiera sido suficiente para que la Segunda Sala emitiera una nueva jurisprudencia en sentido contrario.

Las ideas expuestas por el ministro Juan Díaz Romero ${ }^{31}$ en el correspondiente voto particular evidencian lo extraordinario del caso, en los términos siguientes:

Ahora bien, la solicitud de modificación de jurisprudencia encuentra su razón de ser en brindar la oportunidad a un órgano jurisdiccional de menor jerarquía de que, aun cuando se encuentra obligado en cada caso concreto a aplicar la jurisprudencia sustentada por órganos superiores, una vez aplicado el criterio respectivo, si considera que existen motivos suficientes para que en su caso pudiera ser modificado, elevar la petición respectiva al órgano emisor del criterio jurisprudencial.

Por tal motivo es que se reconoce a los tribunales colegiados de circuito la posibilidad de solicitar la modificación de algún criterio sustentado por el Pleno o las salas, así como se reconoce a los ministros de estas últimas, al igual que al ministro presidente, la facultad de solicitar la modificación de una jurisprudencia establecida por el tribunal Pleno.

31 Conviene destacar que este ministro fue quien presentó el proyecto inicial en el amparo en revisión 1133/2004, discutido por el Pleno en las sesiones públicas del 10, 12 y 16 de enero de 2006, que finalmente no fue aprobado. 
En este sentido, conviene precisar que la facultad para solicitar la modificación de jurisprudencia sustentada por el Pleno se encuentra dirigida tanto a los tribunales colegiados de circuito como a las salas; mientras que respecto de la jurisprudencia sustentada por estas últimas, la legitimación para solicitar su modificación corresponde en forma exclusiva a los tribunales colegiados de circuito, o bien, a los magistrados que los integran.

\section{Otro cambio de criterio por la Segunda Sala}

Sorprendente, por ello, resultó que unos meses después la propia Segunda Sala de la SCJN se desdijera de los términos plenos asignados a la garantía de audiencia previa en el ámbito expropiatorio, para reconocer, con fundamento en la Ley de Expropiación y no en la Constitución, algunos casos de excepción, según consta en la tesis 2a. LXI/2007, que señala:

La Segunda Sala de la Suprema Corte de Justicia de la Nación en la jurisprudencia 2a./J. 124/2006, publicada en el Semanario Judicial de la Federación y su Gaceta, novena época, t. XXIV, septiembre de 2006, p. 278, sostuvo que la expropiación es un acto privativo de la propiedad y, por tanto, previamente a la emisión del decreto correspondiente debe respetarse la garantía de audiencia establecida en el artículo 14 de la Constitución Política de los Estados Unidos Mexicanos. Sin embargo, dicho criterio admite excepciones, pues del artículo 8o. de la Ley de Expropiación se infiere que la defensa del gobernado puede otorgarse después de la ejecución de ese acto privativo aunque sea impugnado, siempre y cuando la declaratoria se realice invocando como causas de utilidad pública las previstas en las fracciones V, VI y X de su artículo 1o., cuyo objeto es: a) satisfacer necesidades colectivas en caso de guerra $\mathrm{o}$ trastornos interiores $(\mathrm{V})$; b) abastecer a las ciudades o centros de población de víveres u otros artículos de consumo necesario (V); c) combatir o impedir la propagación de epidemias, epizootias, incendios, plagas, inundaciones u otras calamidades públicas (V); d) constituir medios para la defensa nacional o para el mantenimiento de la paz pública (VI); y, e) evitar la destrucción de los elementos naturales y los daños que la propiedad pueda sufrir en perjuicio de la colectividad (X); supuestos en los cuales, la ocupación del bien expropiado puede realizarse inmediatamente después de la declaratoria correspondiente, sin oír previamente al afectado, pero respetando su garantía de audiencia con posterioridad y antes de que el Estado disponga definitivamente de la propiedad, en virtud del carácter urgente e inaplazable de esa medida. ${ }^{32}$

32 Semanario Judicial de la Federación y su Gaceta, t. XXV, junio de 2007, p. 342, registro 172,220, tesis 2a. LXI/2007, "EXPROPIACIÓN. SI LA DECLARATORIA SE REALIZA 
El contraste explícito en las decisiones antes señaladas es evidente. Por un lado, tanto el Pleno como la Segunda Sala de la SCJN —ésta en la jurisprudencia 2a./J. 124/2006 - concluyeron que la garantía de audiencia previa rige a plenitud en materia expropiatoria. El fundamento de esta afirmación es que ni el artículo 27, segundo párrafo, de la Constitución ni alguna otra de sus disposiciones establecen excepción alguna sobre el particular. En lenguaje llano, ello significa que dicha garantía opera en todos los casos, incluso en situaciones de urgencia o apremio, como consta en el engrose, realizado por la ministra Margarita Beatriz Luna Ramos, como ya se ha apuntado, de la ejecutoria emitida por el Pleno en el amparo en revisión 1133/2004. Del análisis de las respectivas decisiones se desprende que si el texto constitucional no permite excepciones, la SCJN no tendría por qué concederlas.

Sin embargo, la Segunda Sala, en su tesis 2a. LXI/2007, modifica esa conclusión, para sostener ahora que en ciertos casos de urgencia o apremio la garantía de audiencia previa sí sufre excepciones. Esto es a todas luces desconcertante, pues las razones ahí dadas entran en franca contradicción con las consideraciones expuestas en las sesiones públicas del Pleno de la SCJN los días 10, 12 y 16 de enero de 2006, desarrolladas en la ejecutoria emitida en el amparo en revisión 1133/2004, que al final de cuentas fue la causa fundante para que la Segunda Sala modificara la vieja jurisprudencia 834 y emitiera una nueva identificada con el número 2a./J. 124/2006.

A su vez, la tesis 2a. LXI/2007 pone en duda la pertinencia constitucional de que las excepciones se hubieran elaborado a partir de lo dispuesto por la Ley de Expropiación, pues es inadmisible, de acuerdo con una correcta hermenéutica jurídica, que los contenidos constitucionales se definan con criterios apoyados en la legislación ordinaria. Con esto lo que se pretende evidenciar es que, en aras de atemperar los potenciales efectos de una aplicación rígida de la garantía de audiencia previa en la expropiación, la SCJN hizo uso de un remiendo interpretativo de difícil asimilación constitucional.

INVOCANDO COMO CAUSAS DE UTILIDAD PÚBLICA LAS PREVISTAS EN LAS FRACCIONES V, VI Y X DEL ARTÍCULO 1o. DE LA LEY RELATIVA, NO SE REQUIERE OTORGAMIENTO DE LA GARANTÍA DE AUDIENCIA PREVIAMENTE A LA OCUPACIÓN DEL BIEN EXPROPIADO". 
De igual modo, la parte final de la tesis 2a. LXI/2007 amerita comentarios especiales, por cuanto que señala que, en casos de excepción,

la ocupación del bien expropiado puede realizarse inmediatamente después de la declaratoria correspondiente, sin oír previamente al afectado, pero respetando su garantía de audiencia con posterioridad y antes de que el Estado disponga definitivamente de la propiedad, en virtud del carácter urgente e inaplazable de esa medida.

A estas justificaciones dadas por la Segunda Sala de la SCJN, es dable efectuarle los comentarios siguientes:

- La ocupación de los bienes es un acto posterior que se configura como consecuencia de los decretos expropiatorios - éstos son la causa de aquélla-, y ambos son distintos de la disposición definitiva de la propiedad por parte del Estado. El manejo confuso de esta tríada prescinde de una realidad objetiva: el acto jurídico que consuma la privación de la propiedad en perjuicio de los particulares, lo constituyen los decretos expropiatorios. Por ende, es respecto de éstos, y no de los efectos posesorios subsecuentes, por los que se debe resolver si debe o no respetarse la garantía de audiencia en forma previa. La simple lógica impide aceptar como válida la secuencia argumentativa de la tesis en cita.

- En cualquier caso, no sólo en los supuestos señalados en la tesis $2 a$. LXI/2007, los afectados tienen derecho a la defensa de sus intereses con posterioridad a la expropiación, sea a través del recurso administrativo o del juicio de amparo. Ello, por lo tanto, no es justificación suficiente para reconocer excepciones casuísticas a la garantía de audiencia previa. Si así fuera, en todos los casos procederían estas excepciones, más aún cuando las mismas coincidieran con hipótesis extraídas de la Ley de Expropiación, y no de la Constitución.

- Los efectos posteriores a la expropiación, como son la ocupación de los bienes y la disposición definitiva de éstos por parte del Estado, jurídicamente no consuman la privación de la propiedad. Por ende, que tales efectos se impidan dependerá de que los mismos puedan suspenderse mediante el recurso administrativo o el juicio de amparo. Estas valoraciones corresponden de suyo a los medios de 
defensa ex post que se intenten en contra de los decretos expropiatorios, y no de la eficacia previa de la garantía de audiencia. La tesis 2a. LXI/2007 propicia la confusión de los momentos — la tríada de situaciones - que se presentan en la materia: expropiación, ocupación y disposición definitiva de los bienes.

\section{El tema de los tratados internacionales de libre comercio}

Como se señaló, en las sesiones públicas de 10, 12 y 16 de enero de 2006 del Pleno de la SCJN, los ministros Sergio Salvador Aguirre Anguiano y Genaro David Góngora Pimentel sostuvieron que el respeto previo de la garantía de audiencia en la expropiación encuentra su explicación y exigencia en los tratados de libre comercio celebrados por México con diversos país, en particular el Tratado de Libre Comercio de América del Norte (TLCAN). ${ }^{33} \mathrm{Al}$ respecto, en el engrose de la ejecutoria emitida en el amparo en revisión número 1133/2004 (folio 121), en forma escueta y tangencial se señala:

La conclusión a la que se ha arribado es acorde a la interpretación sistemática y armónica de los artículos 14 y 27 de la Constitución federal, pero además resulta congruente con el principio de no discriminación por razón de nacionalidad previsto en el artículo 1o. constitucional y 1o. de la Convención Americana sobre Derechos Humanos [sic], que aplicado directamente al caso concreto, debió orillar a la autoridad a prever para las empresas nacionales las mismas condicionales que las reguladas para los extranjeros en el Tratado de Libre Comercio de América del Norte, en cuanto al aspecto en análisis.

Al efecto, el artículo 1110. "Expropiación e indemnización” del TLCAN establece, en lo conducente, lo siguiente:

1. Ninguna de las Partes podrá nacionalizar ni expropiar, directa o indirectamente, una inversión de un inversionista de otra Parte en su territorio, ni adoptar ninguna medida equivalente a la expropiación o nacionalización de esa inversión (expropiación), salvo que sea:

(a) por causa de utilidad pública;

33 El texto del TLCAN fue publicado en el Diario Oficial de la Federación del 20 de diciembre de 1993. 
(b) sobre bases no discriminatorias:

(c) con apego al principio de legalidad y al artículo $1105(1) ;{ }^{34} \mathrm{y}$

(d) mediante indemnización conforme a los párrafos 2 a 6 .

2. La indemnización será equivalente al valor justo de mercado que tenga la inversión expropiada inmediatamente antes de que la medida expropiatoria se haya llevado a cabo (fecha de expropiación), y no reflejará ningún cambio en el valor debido a que la intención de expropiar se conoció con antelación a la fecha de expropiación. Los criterios de valuación incluirán el valor corriente, el valor del activo (incluyendo el valor fiscal declarado de bienes tangibles), así como otros criterios que resulten apropiados para determinar el valor justo de mercado.

3. El pago de la indemnización se hará sin demora y será completamente liquidable.

4. En caso de que la indemnización sea pagada en la moneda de un país miembro del Grupo de los Siete, la indemnización incluirá intereses a una tasa comercial razonable para la moneda en que dicho pago se realice, a partir de la fecha de la expropiación hasta la fecha de pago.

De esta disposición se desprenden varios comentarios. El primero es que, como resulta de la anterior transcripción, el TLCAN nada dispone en torno a la garantía de audiencia previa en materia expropiatoria. Del citado artículo ni siquiera puede sustentarse que la indemnización tenga que pagarse en forma previa a la expropiación, pues lo único que dispone su párrafo (1) (d) es que se haga "mediante indemnización", con la precisión establecida en su párrafo (3) de que: "El pago de la indemnización se hará sin demora". De ahí la incorrección en que incurre la SCJN sobre el particular. Tan es así, que el párrafo (4) del mismo precepto reconoce la generación de intereses desde la fecha de la expropiación y hasta el pago de la respectiva indemnización.

Podría decirse que del texto en inglés del artículo 1110 del TLCAN, por cuanto que instituye el due process of law en la expropiación, puede desprenderse la vigencia de la garantía de audiencia previa en México. Sin embargo, este planteamiento enfrenta tres retos de especial complejidad: el primero, que el texto en español es el vigente en nuestro país y,

34 El artículo 1105(1) "Nivel mínimo de trato" del TLCAN dispone: "Cada una de las Partes otorgará a las inversiones de los inversionistas de otra Parte, trato acorde con el derecho internacional, incluido trato justo y equitativo, así como protección y seguridad plenas". 
por lo tanto, el aplicable por los órganos del Estado; el segundo, que el Pleno de la SCJN nunca aludió a esa situación, es decir, al contenido normativo del texto en inglés del TLCAN; y tercero, que en las sesiones públicas de enero de 2006 y en la ejecutoria dictada en el amparo en revisión 1133/2004 no se mencionan problemas de interpretación legal de dicho precepto, ni se señala la conveniencia de acudir a principios de derecho internacional para solucionarlo. De ahí que el punto del due process of law deba desestimarse por completo.

Lo anterior, por tanto, impide tener como válida la aseveración dogmática realizada en otro momento - sesión pública del 25 de febrero de 1997- por el ministro Sergio Salvador Aguirre Anguiano, al resolver el amparo en revisión 1565/94, en los términos siguientes:

Éste es, como inicialmente lo señalé, un argumento de refuerzo, ¿qué es lo que refuerza?, bueno, que el Ejecutivo federal y el Senado de la República tan coincidieron en que la audiencia debía ser previa, que en los tratados internacionales que celebran en la actualidad y referidos a la materia expropiatoria, conceden a los extranjeros la audiencia previa. No existe pues el conflicto de que el tratado internacional pueda ser inconstitucional; pero si así se considerara, estaríamos en presencia de un fuero para los extranjeros, porque ellos tendrían un estatuto de privilegio del que carecerían los mexicanos, ya que éstos sí se les podría expropiar sin previa audiencia y a aquéllos no se les podría expropiar sin previa audiencia.

La complejidad para justificar en el TLCAN la existencia de la garantía de audiencia previa, quedó reflejada en el voto particular de minoría - en ese entonces no hubo quórum para modificar la jurisprudencia P./J. 65/95-, pues del mismo no se desarrollan ideas fehacientes que así lo demuestren; antes bien, lo que consta es una presentación compleja, de difícil asimilación lógica y jurídica, como consta en la parte relativa que a continuación se transcribe:

Desde luego, con la sola mención "con antelación" no implica la existencia de ningún procedimiento previo a la expropiación, aquí, en este artículo [1110 del TLCAN]. Pero en el propio tratado, en el capítulo XX, que se inicia con 1 artículo 2001, se previenen las "Disposiciones institucionales y procedimientos para la solución de controversias", conforme a las cuales las partes resolverán los conflictos que surjan por la aplicación de dicho tratado. 
Es decir, como se advierte de lo anterior, en el Tratado del Libre Comercio sí se contempla la audiencia previa a la expropiación, pues las partes, antes de que se ejecute dicha medida — en tratándose de canadienses y estadounidenses - tienen que ponerse de acuerdo respecto de la indemnización; si no llegan a ningún acuerdo, entonces se someterán a los procedimientos conciliatorios y de arbitraje o al procedimiento ante los paneles para resolver sus conflictos; y mientras no haya consenso respecto de la indemnización, no habrá expropiación.

Lo anterior, además, presenta algunos inconvenientes metodológicos: el primero, que del artículo 2001, o de cualquier otro del capítulo XX del TLCAN, no se desprende de manera incuestionable, como pretende dicho voto minoritario, que el tema de la indemnización tenga que arreglarse con anterioridad a que se decrete la expropiación; y el segundo, que no se transcriben siquiera las disposiciones pertinentes del capítulo $\mathrm{XX}-\mathrm{u}$ otras - del TLCAN que soporten esa afirmación, mucho menos para cuadrarlas con la materia expropiatoria. En todo caso, como la indemnización es una parte del fenómeno expropiatorio, la misma nada tiene que ver con el otro tema sustantivo concerniente a la existencia de un causa pública que la justifique, respecto del cual los alcances de la garantía de audiencia - previa o no - tienen una connotación y alcances distintos a los de la sola indemnización, como lo adujo el ministro Juan N. Silva Meza en la sesión pública del 10 de enero de 2006, en los términos siguientes:

Ahora en la actualidad... sabemos que esos procedimientos de expropiación para determinar por ejemplo, la causa de utilidad pública, en la mayoría de los casos requieren de un análisis técnico, dictámenes periciales de muchas situaciones que hacen indispensable la presencia ya no solamente en función del cumplimiento de un derecho fundamental antes de que te prive de este derecho fundamental que tienes para la propiedad privada, necesito oírte...

Incluso, aun cuando del TLCAN pudiera elaborarse la justificación expuestas en el voto de la minoría, adicionalmente ello conllevaría el reto de resolver, en primer término, la incompatibilidad - confrontación- normativa entre las disposiciones de ese tratado y los artículos 10 a 20 de la Ley de Expropiación y 521 a 529 del Código Federal del Procedimientos Civiles, de los que se corrobora que en México la indemnización no es previa, cuya validez constitucional ha sido sostenida por la 
SCJN al interpretar el artículo 27, segundo párrafo, de la Constitución. Otro reto sería definir cómo operarían las disposiciones del TLCAN en relación con el artículo 27, fracción VI, segundo párrafo de la Constitución, ${ }^{35}$ que en relación con el tema de la indemnización ordena la intervención de autoridad judicial. De nada de ello se ocupa el citado voto de la minoría.

En relación con este tema - garantía de audiencia previa e indemnización - cabe una última reflexión. En diferentes momentos de la sesión pública del 10 de enero de 2006, fueron varios los ministros que señalaron la oportunidad y la conveniencia de suplir "un poco la deficiencia del concepto de violación", como justificación para resolverlo. Sin embargo, llama poderosamente la atención que en las subsecuentes sesiones públicas y, sobre todo, en la ejecutoria dictada en al amparo en revisión $1133 / 2004$, no se haya vuelto a tocar el asunto. En fin, un dato menor que evidencia los vaivenes de la SCJN sobre el particular.

\section{Cómo respetar la garantía de audiencia previa}

En razón de que la $\mathrm{SCJN}$ exige ahora el respeto previo de la garantía de audiencia en el tema expropiatorio - con las excepciones apuntadas en la tesis 2a. LXI/2007-, para efectos constitucionales debe definirse cómo, de qué manera y ante quién — autoridad administrativa o jurisdiccional- deben tramitarse los procedimientos expropiatorios, incluyendo la integración del expediente respectivo.

Las opciones serían, por una parte, que la garantía de audiencia previa se cumpliera ante los tribunales federales, o, en cambio, ante las propias autoridades administrativas. De cada una de esas opciones nos ocuparemos a continuación.

a) A partir del cambio de criterio en relación con la garantía de audiencia previa en la expropiación, una alternativa sería reformular la interpretación del artículo 27, fracción VI, tercer párrafo, de la Constitución, con el propósito de que esa garantía individual operase en exclusiva

35 Este precepto establece lo siguiente: "El exceso de valor o el demérito que haya tenido la propiedad particular por las mejoras o deterioros ocurridos con posterioridad a la fecha de la asignación del valor fiscal, será lo único que deberá quedar sujeto a juicio pericial y a resolución judicial. Esto mismo se observará cuando se trate de objetos cuyo valor no esté fijado en las oficinas rentísticas". 
ante los tribunales judiciales, lo cual ameritaría un pronunciamiento específico de la SCJN sobre el particular.

Esta sería una interpretación que trastocaría los esquemas que han operado tradicionalmente en México. Si procediese, la consecuencia sería que la participación de las autoridades administrativas se reduciría a la emisión de la declaratoria de utilidad pública y a la tramitación de los expedientes respectivos, en términos de los artículos 1o., 2o. y 3o. de la Ley de Expropiación, lo que, a su vez, sería la causa fundamental para que los tribunales resolvieran los propios expedientes - dando intervención formal y material a los afectados - y, en su caso, decretaran las expropiaciones.

En soporte de estas ideas, de algo son útiles las vertidas por el ministro José de Jesús Gudiño Pelayo en la sesión pública del 10 de enero de 2006, que sin referirse en específico a este tema, incidentalmente resultan aplicables. Dichas ideas fueron las siguientes:

Es evidente que aquí [artículo 27, fracción VI, tercer párrafo, de la Constitución] no está mencionando la audiencia previa, pero sí queda claro también, que la audiencia previa va de acuerdo con el espíritu que establece este tercer párrafo, por qué, porque solamente la ocupación se haría efectiva por medio de procedimiento judicial, pero dentro de este procedimiento y por orden de los tribunales correspondientes que se dictará en el plazo máximo de un mes, las autoridades administrativas procederán desde luego a la ocupación, administración, etcétera; es decir, se requiere este procedimiento judicial previo para la ocupación, esto empata perfectamente con la audiencia previa; entonces la audiencia previa sí se encuentra dentro del espíritu del artículo 27 constitucional, como se demuestra aquí claramente.

b) La otra posibilidad para el cumplimiento previo de la garantía de audiencia, es que se siga aplicando la añeja jurisprudencia - la denominada tesis Fraga-, de acuerdo con la cual la interpretación del artículo 14, segundo párrafo de la Constitución permite que toda actuación de las autoridades administrativas se asimile a un "juicio seguido ante los tribunales previamente establecidos". Lo anterior se ratifica de manera expresa en la ejecutoria emitida por el Pleno de la SCJN en el amparo en revisión 1133/2004 [folios 82 y 83], en los siguientes términos:

Conforme a esas ideas, no puede sostenerse válidamente que el concepto "juicio" contenido en el segundo párrafo del artículo 14 constitucional, deba 
consistir necesariamente en un verdadero y auténtico proceso que se siga ante las autoridades judiciales.

Desde esa óptica, el concepto de "juicio", que es de capital importancia para fijar el sentido mismo de la garantía específica de audiencia en estudio, equivale a la idea de procedimiento, es decir, de una secuela de actos concatenados entre sí afectos a un fin común que les proporciona unidad.

En ese sentido, el "juicio" a que alude el artículo 14, segundo párrafo, de la Constitución federal, no necesariamente supone un real y verdadero conflicto jurídico que deba ser resuelto a través de una resolución jurisdiccional, en sentido material, sino que dicho conflicto puede ser presuntivo o real.

En suma, el carácter normativo de la Constitución impone incluso a las autoridades administrativas del Estado la obligación positiva de observar directamente, frente al gobernado, una conducta activa, que estriba en realizar todos y cada uno de los actos que tiendan al cumplimiento de las exigencias específicas en que el derecho de audiencia se revela.

Ello significa, por ende, que el Pleno de la SCJN confirma que la garantía de audiencia previa en la expropiación tiene que cumplirse en sede administrativa, con la aparente complicación, en su opinión (folio 78), de que como la Ley de Expropiación no establece regulación alguna sobre el particular:

... ello no debe impedir que la autoridad administrativa otorgue la oportunidad de defensa al particular afectado, en aplicación directa de la Constitución.

Las dificultades de ese entendimiento consistieron en que podría sustentar, de un lado, la idea de que las autoridades administrativas tendrían la posibilidad de ejercer un control difuso de la constitucionalidad de la ley respectiva, en contravención a los artículos 103 y 133 constitucionales, y de otro, la idea de que la ausencia de un procedimiento previsto por el legislador daría lugar a la posibilidad de que fuera la autoridad administrativa quien creara una normatividad ad hoc en ese sentido, relativizando el principio de legalidad.

A criterio del Pleno de la SCJN, en los casos en que las leyes de la materia carezcan de un procedimiento que asegure la garantía de audiencia previa, el problema para las autoridades administrativas será que carecerán de un fundamento legal que lo sustente, poniendo en entredicho, por ende, que los procedimientos expropiatorios pudieran "cumplir con 
las formalidades esenciales" y que se practicaran "conforme a las leyes expedidas con anterioridad al hecho". ${ }^{36}$

La solución al tema se da en la propia ejecutoria recaída en el amparo en revisión 1133/2004 (folios 79 y 80), en los términos siguientes:

Este alto tribunal observa que la primera objeción no tiene lugar... en efecto, en ese caso, se estaría, más bien, ante la presencia de una labor integrativa, de aplicación directa de la Constitución, como deber de todos los poderes públicos a su observancia, sin que ello implique la inaplicación de alguna norma secundaria en el caso concreto (que es el límite de la eficacia directa de la norma suprema en nuestro sistema constitucional).

La segunda objeción tampoco encuentra sustento, toda vez que la ausencia de un procedimiento de audiencia en la ley del acto genera la necesidad constitucional — como deber de la autoridad - de colmar la laguna legal respectiva a través de la aplicación de los principios generales del derecho, a fin de garantizar que el particular sea oído, y vencido en juicio, en orden a cumplir con el segundo párrafo del artículo 14 constitucional.

El vacío normativo, en esos casos, no da lugar a una creación normativa ad hoc proveniente de autoridad administrativa, puesto que dicha laguna puede colmarse con los elementos mínimos que la jurisprudencia ha exigido como formalidades esenciales del procedimiento...

Estas complicaciones, sin embargo, habría que ponerlas en duda, de ser procedente el argumento de que en materia expropiatoria se surte la aplicación de la Ley Federal de Procedimiento Administrativo, tanto en lo que hace a la instrucción de los procedimientos y a la integración de los expedientes, como en lo que respecta al recurso administrativo, en términos de su artículo 1o., primero y tercer párrafos, que establece:

Las disposiciones de esta Ley son de orden e interés públicos, y se aplicarán a los actos, procedimientos y resoluciones de la administración pública federal centralizada, sin perjuicio de lo dispuesto en los tratados internacionales de los que México sea parte.

36 Esta situación es la que subyace en la discusión sobre el modo en que las autoridades administrativas tendrán que cumplir la garantía de audiencia previa (formalidades, plazos, términos, alegaciones, probanzas, etcétera), en tanto la legislación federal y local no se reforme para cumplir con el nuevo criterio de la SCJN. 
Este ordenamiento no será aplicable a las materia de carácter fiscal, responsabilidades de los servidores públicos, justicia agraria y laboral, ni al Ministerio Público en ejercicio de sus funciones constitucionales. En relación con las materias de competencia, prácticas desleales de comercio internacional y financiera, únicamente les será aplicable el título tercero A.

De esta manera, como la materia expropiatoria se corresponde con actos, procedimientos y resoluciones de la administración pública federal centralizada, y como la misma no se ubica en las excepciones ahí mismo indicadas, parecería que la conclusión obligada que la Ley Federal de Procedimiento Administrativo es enteramente aplicable en la especie. Esta consideración se omite en la ejecutoria emitida en el amparo en revisión 1133/2004, sobro todo si se tiene presente que cuando se trata de expropiaciones del gobierno del Distrito Federal, en las que rige la misma Ley de Expropiación, expresamente se acepta la aplicación de la Ley de Procedimiento Administrativo del Distrito Federal, según consta en el criterio de la Segunda Sala de la SCJN que a continuación se transcribe:

Si bien es cierto que del citado precepto se advierte que los afectados por un decreto expropiatorio emitido por el jefe de gobierno del Distrito Federal pueden impugnarlo a través del recurso administrativo de revocación, cuya tramitación y resolución competen a la Consejería Jurídica y de Servicios Legales, conforme al artículo 35 de la Ley Orgánica de la Administración Pública del Distrito Federal, también lo es que la regulación de ese medio de impugnación se complementa con los artículos 5o., 6o., 7o. y 8o. de la Ley de Expropiación, y 39 de la Ley de Procedimiento Administrativo del Distrito Federal... Lo anterior demuestra que el artículo 20 bis de la Ley de Expropiación no viola la garantía de audiencia contenida en el artículo 14 de la Constitución Política de los Estados Unidos Mexicanos, pues en concordancia con los preceptos mencionados se da certeza al gobernado respecto de la autoridad ante quien ha de interponerse el recurso y del plazo que se tiene para hacerlo; se le otorga la oportunidad de ofrecer y desahogar las pruebas en que finque su defensa, así como de presentar alegatos, además de imponer a la autoridad que conozca de ese medio impugnativo la obligación de dictar la resolución respectiva en un plazo claramente determinado. ${ }^{37}$

37 Semanario Judicial de la Federación y su Gaceta, t. XXV, marzo de 2007, p. 709, registro 172,902, tesis 2a. XXVI/2007, "REVOCACIÓN. EL ARTíCULO 20 BIS DE LA LEY DE EXPROPIACIÓN QUE PREVÉ EL RECURSO ADMINISTRATIVO RELATIVO, NO VIOLA LA GARANTÍA DE AUDIENCIA". 
Múltiples han sido los criterios de la SCJN que han reiterado el mandato de que el Poder Legislativo está obligado a instituir los procedimientos legales por los que se respete la garantía de audiencia previa para los particulares, los cuales han servido de sustento de la siguiente jurisprudencia:

La garantía de audiencia debe constituir un derecho de los particulares, no sólo frente a las autoridades administrativas y judiciales, sino también frente a la autoridad legislativa, que queda obligada a consignar en sus leyes los procedimientos necesarios para que se oiga a los interesados y se les dé oportunidad de defensa en aquellos casos en que resulten afectados sus derechos. Tal obligación constitucional se circunscribe a señalar el procedimiento aludido; pero no debe ampliarse el criterio hasta el extremo de que los órganos legislativos estén obligados a oír a los posibles afectados por una ley antes de que ésta se expida, ya que resulta imposible saber de antemano cuáles son todas aquellas personas que en concreto serán afectadas por la ley y, por otra parte, el proceso de formación de las leyes corresponde exclusivamente a órganos públicos. ${ }^{38}$

\section{Un tema complementario}

La ejecutoria dictada en el amparo en revisión 1133/2004 (folios 119 y 120) se ocupa de un tema que, aunque incidental, tiene importancia en cuanto que fue utilizado para reafirmar el respeto previo de la garantía de audiencia en la expropiación. El mismo se desarrolla de la manera siguiente:

... por otro lado, porque la emisión de actos expropiatorios declarados judicialmente injustificados ha tendido a generar afectaciones irreversibles sobre los bienes que concretamente han sido objeto de la expropiación, debido a problemas que la experiencia del presente momento histórico ha evidenciado en relación con la ejecución de ese tipo de sentencias.

38 Semanario Judicial de la Federación, Apéndice 2000, t. I, p. 142, registro 900,111, jurisprudencia 111, “AUDIENCIA, GARANTÍA DE. OBLIGACIONES DEL PODER LEGISLATIVO FRENTE A LOS PARTICULARES”. Los primeros criterios que sobre este particular fueron emitidos por la SCJN datan de 1946. Éstos y todos los subsecuentes hasta llegar a constituir la jurisprudencia en cita, se relacionan con diferentes rubros identificados con la garantía de audiencia del artículo 14 de la Constitución, algunos de los cuales tienen asignados los registros siguientes: 321,$798 ; 321,813 ; 320,264 ; 320,048 ; 322,869$; 319,$858 ; 319,933 ; 319,761 ; 319,508 ; 805,225 ; 318,140 ; 800,822 ; 805,923 ;$ у 233,745 . 
Si frente al acto de expropiación no procediera audiencia previa, está claro que todo decreto expropiatorio sería casi definitivo, ningún mecanismo de defensa sería efectivo para combatir un acto de expropiación, puesto que el transcurso del tiempo y la firmeza temporal del acto expropiatorio, terminaría por hacer imposible la devolución de la propiedad concretamente afectada al gobernado, en caso de tener éxito en los tribunales.

El punto que destaca de esta transcripción es que de insistirse en que "no procediera audiencia previa", en el presente, se haría extensiva la imposibilidad que en el pasado ha representado el cumplimiento de las ejecutorias de amparo. Este silogismo tiene algunas inconsistencias metodológicas importantes, por el hecho de que se traslapan y confunden tres distintos momentos jurídico-procesales:

1. El respeto de la garantía de audiencia por las autoridades administrativas con anterioridad a la emisión de los decretos expropiatorios;

2. Los efectos propios de la expropiación, es decir, la privación inmediata y directa de la propiedad de los gobernados, la transmisión de la misma y la toma de posesión de los bienes por parte del Estado, y el pago de la indemnización a los afectados, y

3. Los efectos restitutorios de los amparos.

En efecto, la confusión se actualiza porque la garantía de audiencia - previa o no- nada tiene que ver, directa o indirectamente, con los efectos restitutorios del amparo. La anterior secuencia argumentativa, conforme al enfoque del Pleno de la SCJN, implícitamente significa que la garantía de audiencia, siendo previa, hace que las expropiaciones estén siempre apegadas a derecho y que, por ende, que los efectos restitutorios estén asegurados, lo cual es inaceptable, pues ello sería tanto como admitir que la garantía de audiencia previa hiciera prácticamente innecesario el juicio de amparo o, peor aún, que el respeto previo de dicha garantía, por sí solo, sustituyese a instituciones estructurales del juicio de amparo. Ni la lógica jurídica ni la práctica forense en diferentes temas administrativos - fiscal, ambiental, propiedad intelectual, competencia económica, etcétera- avalarían una conclusión de ese tipo.

Se está ante un argumento circular, apartado de la ortodoxia jurídica y, por lo tanto, de dudosa validez constitucional. De ahí que los señala- 
mientos acerca de que "todo decreto expropiatorio sería casi definitivo", de que "ningún mecanismo de defensa sería efectivo para combatir un acto de expropiación" y de que "el transcurso del tiempo y la firmeza temporal del acto expropiatorio, terminaría por hacer imposible la devolución de la propiedad", no sean acertados.

De hecho, la circunstancia de que en el pasado se hayan consumado de manera irreparable - irreversible - los efectos de múltiples expropiaciones y el Poder Judicial no haya podido materializar la restitución de la propiedad particular afectada, tampoco es atribuible ni guarda relación alguna con la garantía de audiencia previa, sino propiamente con otra institución de primer orden del juicio de amparo: la suspensión de los actos reclamados, cuya concesión o no depende de las causas de utilidad pública invocadas en cada caso. ${ }^{39} \mathrm{El}$ punto es que cuando las suspensiones se han concedido, pero se han consumado de manera irreparable los efectos de las expropiaciones, ello nada tiene que ver con dicha garantía constitucional, y cuando las suspensiones se han negado, los decretos expropiatorios acarrean sus consecuencias en forma autónoma: privación de la propiedad, transmisión de la misma y toma de posesión de los bienes por parte del Estado, así como pago de la indemnización a los afectados.

Los párrafos transcritos al inicio de este apartado conllevan, en todo caso, un mea culpa por parte del Pleno de la SCJN, al reconocer que históricamente la suspensión de los actos reclamados y los efectos restitutorios del amparo, han sido ineficaces. Sin embargo, lo conducente no es reducir el asunto a si ello se ha debido a la ausencia de una garantía previa de audiencia, sino más bien a si el Poder Judicial de la Federación ha asumido la responsabilidad constitucional de exigir a las autoridades administrativas el acatamiento cabal de las suspensiones y de los amparos concedidos a los particulares.

En la forma que está redactada la ejecutoria emitida en el amparo en revisión 1133/2004, parecería que el Pleno de la SCJN se desentiende de

39 De cualquier manera, de suyo el tema de la suspensión en amparo muestra desacomodos y obsolescencias destacables. Ello obedece a que el mismo está reservado a la competencia de los tribunales colegiados de circuito en todo el país, quienes en función de los variados juicios que se someten a su resolución mantienen criterios divergentes o inconsistentes entre sí. Esto nada tiene de extraño ni criticable, pero lo deseable sería que la SCJN resolviese gradualmente las contradicciones de tesis, a fin de lograr la unicidad jurisprudencial sobre el particular. 
esa responsabilidad, para trasladarla a las autoridades administrativas, como si por el solo hecho de que las autoridades administrativa respetasen de manera previa la garantía de audiencia, en automático fueran a solucionarse ambos problemas: la suspensión de la expropiación y los efectos restitutorios del amparo. Es difícil aceptar una conclusión de esta índole, sobre todo si se tiene presente que la misma es incompatible con la tesis 2a. LXI/2007, que reconoce los casos de excepción - urgencia o apremio - en los que no opera la garantía de audiencia previa.

En cambio, en lo que sí resulta valiosa la exigencia de que la garantía de audiencia sea previa, es que la integración de los respectivos expedientes se hará en sede administrativa, incluyendo lo relacionado con la defensa de los interesados en todas las facetas: fácticas, técnicas y legales. De este modo tendrán que ser las autoridades institucionalmente calificadas para ello, las que instruyan los procedimientos de expropiación, como requisito previo para decretar la expropiación de la propiedad privada, a diferencia de lo que sucedía con la aplicación de la jurisprudencia P./J. 65/95, en la que la integración de los expedientes, por cuanto hacía a la defensa de los afectados, se hacía ex post ante los tribunales federales. Esto, por supuesto, en el entendido de que, efectivamente, existen casos de excepción en los que no opera en forma previa la garantía de audiencia.

\section{CONCLUSIONES}

La jurisprudencia P./J. 65/95, que sostenía que en las expropiaciones no era aplicable la garantía de audiencia previa, fue reformulada expresamente casi 60 años después de la entrada en vigor de la Ley de Expropiación, bajo la cual, debe recordarse, se han practicado todas las expropiaciones en México a nivel federal, incluidas la petrolera de 1938 y la bancaria de 1982, así como las del Distrito Federal, que en determinados momentos generaron conflictos álgidos, políticos y legales con Andrés Manuel López Obrador.

No es que en las décadas anteriores a dicha jurisprudencia no imperara el mismo criterio, sino que era consabido y aceptado sin mayores reflexiones ni cuestionamientos por la SCJN — derivación natural del fuerte régimen presidencial de la época, en cuyo feudo se incluía al gobierno del Distrito Federal-, el paradigma de que en materia expropiatoria no 
operaba la garantía de audiencia previa. Un ejercicio retrospectivo haría impensable que alguno o varios ministros, bajo un criterio opuesto como el que ahora ha sustentado la SCJN, hubieran contradicho la expropiación petrolera decretada por Lázaro Cárdenas o la expropiación bancaria de José López Portillo, después avalada por Miguel de la Madrid. Nada más lejos de esa posibilidad.

El que la expropiación requiera audiencia previa, más allá de los argumentos jurídicos expuestos, suena razonable para evitar la arbitrariedad de la que fueron víctimas muchos individuos durante décadas. Amanecer un día con una propiedad expropiada sin haberlo ni siquiera discutido de antemano con la autoridad es difícil de justificar en un país democrático. Tal discreción abre pie a abusos y poco cuidado en los motivos para expropiar.

Sin embargo, si se mueve sólo una pieza del complejo aparato que ha regulado la expropiación, bien puede haber sido la puntilla final a la capacidad del Estado de volver a hacer una obra importante que requiere terrenos en manos de privados que deben ser expropiados. Entre machetes y amparos serán tantos los obstáculos que se ve difícil hacer obra pública para las que no se tengan los derechos de vía o los terrenos con antelación.

En la práctica esta nueva disposición puede ser tan complicada que haga que expropiar sea casi imposible. En ausencia de procedimientos bien definidos para dar la audiencia previa, se abre un nuevo mundo de recursos en manos del afectado para buscar frenar una expropiación. Todo acto, al momento de pretender notificar la audiencia puede ser reclamado ante los tribunales, los cuales lentamente irán llenando el vacío de falta de procedimientos bien definidos, por ser nueva la medida y no haber una ley para normarlos. Dada la situación de nuestros registros de propiedad, pueden incluso pasar meses tratando de encontrar al legítimo propietario antes de poderle notificar. Una vez encontrado el propietario, una mera falla en la acreditación del que notificó puede frenar el proceso, lo mismo una reclamación de quien diga ser el verdadero propietario.

Para compensar dicha complejidad, se requeriría de una nueva legislación, una autoridad mucho más cuidadosa al momento de expropiar y un cambio de actitud de los tribunales para que no otorguen amparos a la menor presunción durante el proceso de notificación, sino sólo en casos 
donde haya cierta evidencia de inconstitucionalidad en las actuaciones de las autoridades administrativas.

Por ello, es factible anticipar o incluso estimular un impacto de tipo legislativo en esta materia. En la medida que las leyes de expropiación en el ámbito federal y estatal no regulen el procedimiento administrativo encauzado al respeto de la garantía de audiencia en forma previa, los poderes legislativos se verán conminados a reformar tales leyes para cumplir con este requisito.

De no producirse estas reformas, de cualquier modo las autoridades administrativas que tramitan los expedientes expropiatorios, en aras de acatar la reciente decisión de la SCJN, tendrán que conferir a los gobernados la garantía de audiencia previa a la expropiación, en la forma permitida por la citada tesis Fraga.

En el ámbito internacional, Estados con una fuerte capacidad expropiatoria la han conciliado con un complicado proceso que le da al ciudadano una amplia posibilidad de defender sus intereses. Un caso interesante es el de Francia. En el derecho francés, la garantía contra la expropiación se logra después de la Revolución francesa, como respuesta a las arbitrariedades contra los propietarios que el dominio directo por parte del soberano hacía posible, como el que viene de la Nueva España $\mathrm{y}$ es transportado al Estado posrevolucionario mexicano y que sustenta curiosamente a nuestro artículo 27.

Se trata de una respuesta a la capacidad del rey de utilizar el domaine éminent, es decir, la "expropiación por causa de utilidad pública" para ejercer sobre los bienes de sus súbditos el derecho de "reintegro por medio de una indemnización no regulada" para hacerse de las rentas de sus súbditos. ${ }^{40}$

De la Revolución francesa que busca romper con los excesos de la realeza nace una compleja reglamentación para poder expropiar; pero se trata de un marco jurídico claro, tanto para el gobierno como para el gobernado. Nosotros heredamos el dominio directo y su arbitrariedad, ahora queremos remediarlo sin darle aún una reglamentación que no paralice la capacidad del Estado de emprender.

La decisión de 2006 del Pleno de la SCJN, respaldada en 2007 por su Segunda Sala, se suma a una interpretación garantista de la Constitución

40 Gaudemet, Y., Droit administratif des biens, París, Librairie Générale de Droit, 2002, t. 2, p. 286. 
cada vez más dominante. En esta visión de nuestro texto constitucional se valora, sobre casi cualquier otro elemento, el proteger las garantías individuales frente a la autoridad. En otro texto ${ }^{41}$ hemos mostrado cómo esta interpretación le permite a la SCJN jugar un poderoso papel en definir la política tributaria que no tienen los poderes judiciales en países como España o incluso Estados Unidos, donde las cortes supremas son particularmente independientes y celosas de los derechos individuales. Es decir, nuestra autoridad encargada de definir e implementar la política tributaria, tanto el Legislativo como el Ejecutivo, tiene más límites en esta materia de los que enfrentan autoridades de países que consideramos más liberales que nosotros. Estas limitaciones no están señaladas claramente en la Constitución, sino han dependido de la interpretación de los ministros, de su forma de ver el mundo.

La ciencia jurídica dista de ser una ciencia exacta; por eso los ministros pudieron cambiar la interpretación que antes parecía incuestionable. Dado que la SCJN es un cuerpo no electo de manera popular, poner la lupa sobre la lógica e implicaciones de sus decisiones parece ser un tema de mayor importancia de lo que se ha reconocido hasta ahora, y por ello debe ponerse especial empeño en sus contenidos, en las metodologías aplicadas y, sobre todo, en la necesaria constancia y consistencia de sus decisiones.

Con esta y otras decisiones la SCJN está ratificando el peso central que tiene actualmente. Pero también el que dicho peso depende mucho de quiénes la componen y cómo deciden interpretar un texto que da para muchas conclusiones. Como los propios ministros argumentan en las deliberaciones de la sentencia analizada en este artículo, no es que sus antecesores no supieran de derecho, incluso algunos fueron sus maestros y los tratan con mucho respeto a lo largo del debate; simplemente habían puesto énfasis en otros aspectos. Habían preferido destacar ciertos elementos de la Constitución y no los ahora subrayados.

En un contexto donde el poder político ha sido discrecional y abusivo en muchas ocasiones, es comprensible que la amenaza mayor parezca provenir de su falta de límites. Sin embargo, para que el Estado pueda ser garante de los derechos de todos necesitamos una autoridad con los me-

41 Elizondo, C. y Pérez de Acha, L. M., Separación de poderes y garantías individuales: la Suprema Corte y los derechos de los contribuyentes, México, Centro de Investigación y Docencia Económicas, 2005, Documento de Trabajo núm. 13. 
dios jurídicos para erradicar las prácticas de corrupción y enderezar el sistema de justicia en todas sus dimensiones (por ejemplo, que los criminales reciban las penas que les corresponden, que se cobren los impuestos eficientemente, que no haya taxis pirata, o que se realicen obras públicas aunque requieran expropiaciones). Una interpretación radicalmente garantista de la Constitución, sin cuidar las implicaciones de los amparos concedidos, puede dejar a la autoridad con poco margen de maniobra.

Para el gobierno esta decisión implica que le han cambiado las reglas del juego. Si el Estado de derecho implica certidumbre, ahora aquél se enfrenta con un criterio que no se tomó en cuenta al momento de expropiar los ingenios, por no resultar necesario dada la jurisprudencia existente. El costo para el erario está por definirse. No queda claro cómo se contabilizan los recursos inyectados por el gobierno a los ingenios, ni cómo se toman en cuenta los posibles beneficios que hayan tenido los mismos durante el tiempo que fueron ocupados.

El verdadero costo, sin embargo, está por venir. Hay amparos en curso contra muchos decretos de expropiación, tanto federales como locales, nivel en el cual esta sentencia también importa dada la supremacía de las decisiones de la SCJN. Ya con la jurisprudencia firme, se debe respetar en automático su sentido. Incluso si no se argumentó en el juicio de amparo la falta de audiencia como una causal para solicitarlo, el tribunal puede suplir la deficiencia y concederlo. La ley no puede ser retroactiva en perjuicio del ciudadano, pero sí en su beneficio. Un amparo que lleve décadas en los tribunales puede beneficiarse de esta nueva interpretación. Nadie sabe cuánto puede esto costar al erario, es decir, a todos nosotros. La justicia debe ser ciega, pero no a las implicaciones de sus actos. Menos cuando se está cambiando una interpretación que estuvo vigente 70 años.

En una expropiación en sentido estricto no se priva a un particular de un derecho, no se le confisca, sino que se le intercambia por su valor. Lo que la autoridad debe probar es que hay una causa de interés público para imponer su decisión, pero se debe pagar al precio de mercado, el existente antes de las acciones del gobierno. Por lo menos esa es la lógica de la expropiación en Francia. En relación con este tema, Fernández del Castillo comenta: 
el Estado, al quitar sus bienes a un individuo para destinarlos a satisfacer necesidades públicas, debe indemnizarlo, y así lo consagra expresamente nuestra Constitución.

Indemnizar es resarcir el daño, o sea la pérdida o menoscabo que se sufre en el patrimonio... En el derecho común, el daño se repara restituyendo la cosa al estado en que se encontraba antes de sufrirlo, o entregando otra del mismo género y calidad, de manera que el patrimonio vuelva a quedar igual a como se encontraba anteriormente, sólo en caso de que esos medios de liberación no sean posibles, es cuando debe resarcirse el daño cubriendo su valor en dinero. Pero tratándose de expropiación, esta última solución es la única posible, puesto que la cosa expropiada desaparece jurídicamente por completo para el antiguo propietario... ${ }^{42}$

Esta opinión fue justamente respaldada por la SCJN en la ejecutoria emitida en el amparo en revisión 1133/2004, en los términos siguientes:

La expropiación, aunque sea un acto autoritario unilateral del Estado, tiene la apariencia de una venta forzosa. Por tal causa, dicho acto no es gratuito, sino oneroso. Es decir, el Estado al expropiar a un particular un bien, al adquirir éste, tiene que otorgar a favor del afectado una contraprestación, la cual recibe el nombre de indemnización. A ella se refiere el artículo 27 constitucional al establecer que las expropiaciones sólo podrán hacerse por causa de utilidad pública mediante indemnización. En este sentido, la expropiación no atenta, en principio, contra el estatus general de la propiedad al que presupone; precisamente por ello es por lo que los que padecen la expropiación deben ser compensados pues, de no ser así, contribuirían de un modo desigual y más gravoso, en relación con los no expropiados, a las cargas públicas: la indemnización supone, además de la compensación, el expediente para repercutir el sacrificio sobre toda la colectividad, desde el instante en que es sufragada con los fondos que el sistema fiscal obtiene.

Sin embargo, si la autoridad hace bien su trabajo, logrará expropiar con efectividad los bienes necesarios para desarrollar obras públicas como la construcción de carreteras, presas, escuelas, etcétera. No se puede esperar que le impongan al gobierno el precio de compra, pues, por ejemplo, el particular, sabiendo que se trata del último predio para concluir un aeropuerto, podría exigir contraprestaciones desorbitadas.

42 Fernández del Castillo, G., op. cit., nota 23, p. 87. 
Para conciliar el interés general con el particular debe haber un proceso previo al acto expropiatorio. Si el juicio de amparo revisara la sustancia de los decretos expropiatorios y congelara sus efectos en el propio juicio, podría jugar ese rol conciliatorio.

Pero las implicaciones del juicio de amparo van más allá de la cuestión de expropiación. Mención especial merece el tema del narcotráfico y del crimen organizado. Para enfrentar este serio problema hay que buscar fórmulas que permitan conciliar la defensa de los derechos individuales, incluida la propiedad, con la capacidad del Estado para combatir al crimen organizado. Para ello, es necesario dotar al gobierno de instrumentos de fiscalización (o control) y así contrarrestar la adquisición ilegal de bienes. Una ley de extinción de dominio que permita mecanismos expeditos para la expropiación de bienes en manos del crimen organizado, para que pueda ser operativa en nuestra tradición garantista, va a requerir de un poder judicial capaz de encontrar ese complejo balance.

Con decisiones como las analizadas en este texto, la SCJN está ratificando el peso central que tiene en estos momentos. Pero también el que este peso dependa mucho de quiénes la componen, del contexto en el que operan, de las presiones a las que están sujetos, y de cómo deciden interpretar la Constitución que por su naturaleza da para muchas conclusiones. Como ellos mismos argumentan en las deliberaciones de la sentencia analizada en este artículo, no es que sus antecesores no supieran de derecho, incluso algunos fueron sus maestros y los tratan con mucho respeto a lo largo del debate. Simplemente habían puesto otros énfasis. Habían preferido destacar ciertos elementos de la Constitución y no los ahora subrayados. Estaban también en otro contexto político.

La SCJN está actuando en la práctica como legislador en casos como el acá analizado, aunque la respuesta política en contra de su decisión fue muy limitada. No habría sido igual si el Congreso hubiera limitado la ley de expropiación con un resultado neto en términos de facultades para el Estado no tan distinto del que produce esta nueva jurisprudencia. Esto seguramente obedece a la falta de comprensión en muchos de los actores de las implicaciones de la decisión, dificultad aún más comprensible dado los saltos y contradicciones explicados en este texto.

La tensión entre políticos electos y miembros del Poder Judicial es propia de toda democracia basada en la separación de poderes. Sin em- 
bargo, en México aún falta mucho por pulir. Los límites y decisiones analizados en este texto son sólo algunos de los elementos que necesitan ser revisados para que haya una reforma integral del Poder Judicial. En la medida en la que implicaciones como las aquí anotadas sean reconsideradas, podremos repensar el equilibrio entre los tres poderes. 